\title{
AN ESTIMATION OF THE REAERATION COEFFICIENT IN NATURAL STREAMS BY SPECTRAL ANALYSIS OF TIME SERIES DATA BY TOMONORI MATSUO and NOBUHIRO YOTSUKURA
}




\title{
U.S. DEPARTMENT OF THE INTERIOR JAMES G. WATT, Secretary
}

\author{
GEOLOGICAL SURVEY \\ Doyle G. Frederick, Acting Director
}

For additional information write to:

Chief Hydrologist

U.S. Geological Survey

430 National Center

Reston, Virginia 22092 
Abstract . . . . . . . . . . . . . . . . 1

Introduction . . . . . . . . . . . . . . 2

Equations for dissolved oxygen balance . . . . . . . 3

General one-dimensional equation . . . . . . . . 3

One-dimensional equation for steady uniform flows. . . . 4

Steady-state equations and solutions . . . . . . . 4

Time-dependent equations for a uniform and homogeneous

reach . . . . . . . . . . . . . . . 5

Previous solutions of equation 14 . . . . . . . . . 9

An application of the spectral analysis method . . . . . 10

Recapitulation . . . . . . . . . . . . 10

Revised solutions of equation 14 . . . . . . . . . 10

Application of the spectral analysis method. . . . . . 11

Field data of the Cuyahoga River in Ohio . . . . . . 15

Results of calculations for the Cuyahoga River . . . . 23

Discussion of the spectral method. . . . . . . . . . 28

Consistency between data and model . . . . . . . 28

Maximum digitizing interval and minimum time series

length. . . . . . . . . . . . . . . 36

Reaeration coefficient and river water discharge . . . 36

Conclusions. . . . . . . . . . . . . . . 43

Supplementary information . . . . . . . . . . . . 44

References cited . . . . . . . . . . . . 446

\section{ILLUSTRATIONS}

Figure 1. Power spectrum of DO, Run I-3, the Cuyahoga River at 0ld Portage, Ohio, June 10-15, 1976. . . . 12 
Figure 2. Power spectrum of DO, Run I-5, the Cuyahoga River at 0ld Portage, Ohio, Aug. 23-27, 1976. . . . . . 13

Figure 3. Power spectrum of DO, Run II-3, the Cuyahoga River at Independence, Ohio, July 16-19, 1976 . . . . . . 14

Figure 4. Power spectrum of water temperature, Run I-3, the Cuyahoga River at 0ld Portage, Ohio, June 10-15, 1976 . 16

Figure 5. Power spectrum of water temperature, Run I-5, the Cuyahoga River at 01d Portage, Ohio, Aug. 23-27, 1976 . 17

Figure 6. Power spectrum of water temperature, Run II-3, the Cuyahoga River at Independence, Ohio, July 16-19, 197618

Figure 7. Time series data, Run I-3, the Cuyahoga River at 0ld Portage, Ohio, June 10-15, 1976 . . . . . . . 20

Figure 8. Time series data, Run I-5, the Cuyahoga River at 01d Portage, Ohio, Aug. 23-27, 1976 . . . . . . . . 21

Figure 9. Time series data, Run II-3, the Cuyahoga River at Independence, Ohio, July 16-19, 1976. . . . . . . . 22

Figure 10. Coherency spectrum between sun light intensity and DO, Run I-3, the Cuyahoga River at Old Portage, Ohio, June 10-15, 1976. . . . . . . . . . . . . 24

Figure 11. Coherency spectrum between sun light intensity and saturation concentration of DO, Run I-3, the Cuyahoga River at 0ld Portage, Ohio, June 10-15, 1976. . . . 25

Figure 12. Phase spectrum between sun light intensity and DO, Run I-3, the Cuyahoga River at 0ld Portage, Ohio, June 1015, 1976.................. . . 26

Figure 13. Phase spectrum between sun light intensity and saturation concentration of DO, Run I-3, the Cuyahoga River at 01d Portage, Ohio, June 10-15, 1976 . . . . . . . 27

Figure 14. Power spectrum of sun light intensity, Run I-3, the Cuyahogs River at 01d Portage, Ohio, June 10-11, 1976. (Shortened time series) . . . . . . . . . 38 
Figure 15. Power spectrum of DO, Run I-3, the Cuyahoga River at 01d Portage, Ohio, June 10-11, 1976 (Shortened time series)...... . . . . . . . . 39

Figure 16. Power spectrum of sun light intensity, Run I-3, the Cuyahoga River at 01d Portage, Ohio, June 10-12, 1976. (Shortened time series).......... . 40

Figure 17. Power spectrum of DO, Run I-3, The Cuyahoga River at 01d Portage, Ohio, June 10-12, 1976. (Shortened time series). . . . . . . . . . . . . . . 41

Figure 18. Relations between reaeration coefficient and river discharge at two stations, the Cuyahoga River, Ohio, 1976-1977. . . . . . . . . . . . . . 4 42

\section{TABLES}

Table 1. Description of observation stations, the Cuyahoga, River, Ohio . . . . . . . . . . . . . . 19

Table 2-I. Summary of data and computations, the Cuyahoga River at Old Portage, Ohio . . . . . . . . . . 29

Table 2-II. Summary of data and computations, the Cuyahoga River at Independence, Ohio. . . . . . . . . . . . 30

Table 3-I. Statistical parameters for the predominance of $24-\mathrm{hr}$ periodicty of DO, the Cuyahoga River at Old Portage, Ohio . . . . . . . . . . . . . . . 32

Table 3-II. Statistical parameters for the predominance of $24-\mathrm{hr}$ periodicity of DO, the Cuyahoga River at Independence, Ohio. . . . . . . . . . . . . . . . 33

Table 4. Variation of reaeration coefficient with digitizing interval of time series data (Run I-3 for Cuyahoga River at 0ld Portage, Ohio) . . . . . . . . . . . 37 
AN ESTIMATION OF THE REAERATION COEFFICIENT

IN NATURAL STREAMS BY SPECTRAL ANALYSIS

OF TIME SERIES DATA

By Tomonori Matsuo', Tokyo, Japan

Nobuhiro Yotsukura, Reston, Virginia

\begin{abstract}
Spectral analysis of time series data for the dissolved oxygen concentration (DO), water temperature, and sun light intensity is used to estimate the reaeration coefficient of a natural stream. The stream flow is assumed steady and uniform. Moreover, the reach is assumed biologically homogeneous with respect to activities influencing DO and biochemical oxygen demand (BOD) so that a spatial variation of Do does not exist. Under such conditions, the temporal variation of DO must be caused solely by that of the sun light intensity, which directly influences photosynthetic oxygen production and water temperature, with the latter, in turn, influencing the saturation concentration of DO. The Do mass balance equation under this condition becomes a first-order linear differential equation, which can be solved analytically by means of the Fourier series. The solution indicates that reaeration coefficient can be expressed as a function of the phase shift between the sun light intensity and DO and between the sun light intensity and saturation concentration of DO, and of the Fourier coefficients for the fluctuating portion of the DO and the saturation concentration of DO. Computing these parameters from time series data obtained at a single measurement station, the reaeration coefficient of the Cuyahoga River, Ohio, was estimated to range from 2.6 to $7.7 \mathrm{day}^{-1}$ for two stations during selected periods in 1976 and 1977. Criteria for the selection of suitable data for use of the method were developed and discussed.

I/Associate Professor, the University of Tokyo, Department of Urban Engineering, Tokyo, Japan.
\end{abstract}


The concentration of dissolved oxygen (DO) is one of the most widely used indicators of the extent of organic pollution in natural bodies of water. Also one of the very important aspects of pollution control activities is to predict quantitatively the effect of this organic pollution on DO in water.

With regard to the phenomenon of surface reaeration and its coefficient, a great many research works have been reported with both theoretical and empirical bases, such as the papers by Streeter and Phelps (1925), O'Connor and Dobbins (1958), Churchil and others (1962), Thackston and Krenkel (1969), Bennett and Rathbun (1971), and Brown (1974), just naming a few. However, as pointed out by Rathbun (1977), there still remain considerable difficulties in the estimation or prediction of reaeration coefficient in natural streams.

This paper reports a new method of estimating the reaeration coefficient in natural streams by means of the spectral analysis of time series data for DO, water temperature, and sun light intensity observed at a single station. These data are collected routinely by many water agencies. Because of advancements in instrumentation and automatic recording systems, the accuracy and continuity of these data have been greatly improved in recent years.

The method is based on the assumption that, if a stream reach with steady uniform flow is also biologically homogeneous with respect to oxygen consumption and production processes, the variation of DO is independent of location and becomes a sole function of time. In prototype streams, such conditions may be realized in a reach either upstream from or far downstream of a point source of biological oxygen demand (BOD) so that the source effect is nonexistent or eliminated, and also in a reach where BOD sources are uniformly distributed over the entire length. 
A unique feature of the method is that the spectral analysis of time series data obtained in a prototype stream provides a check on the uniformity and homogeneity of the stream, on which the present analytical model for the reaeration coefficient is founded. Another advantage is the simplicity of the method, namely, that the data are needed only at a single location and the analysis can be done by use of a standard statistical computer program. EQUATIONS FOR DISSOLVED OXYGEN BALANCE

(i) General one-dimensional equation

A general form of the one-dimensional equation for the DO balance in unsteady or nonuniform flows is:

$$
\frac{\partial}{\partial t}(A C)=K_{L} B\left(C_{s}-C\right)-A K_{1} L+A \alpha I-\frac{\partial}{\partial x}(A V C)+\frac{\partial}{\partial x}\left(A D_{x} \frac{\partial C}{\partial x}\right)
$$

Notations in eq. 1 are explained below:

$A$; cross-sectional area,

$B$; width of the channel,

$C$; dissolved oxygen concentration (DO),

$C_{s}$; saturation concentration of the dissolved oxygen,

$D_{x}$; longitudinal mixing coefficient, including longitudinal dispersion, turbulent diffusion, and molecular diffusion,

$I$; sun light intensity,

$K_{1}$; deoxygenation coefficent of BOD,

$K_{L}$; 1iquid-film coefficient for reaeration at the surface,

$L$; biochemical oxygen demand (BOD),

$V$; longitudinal velocity,

$\alpha$; rate coefficient for photosynthetic oxygen production,

$t$; time, and

$x$; longitudinal distance. 
The left-hand term of eq 1 is the time rate of change in DO. On the right-hand side of eq 1 , the first term designates the rate of increase of Do by surface reaeration, the second term the rate of decrease of DO due to deoxygenation by BOD, the third term the rate of increase of DO by photosynthesis, and the fourth and fifth terms designate the rate of Do transport by convection and by mixing, respectively. Except for $A, B, t$, and $x$, all variables and coefficients are averaged quantities over a cross section.

(ii) One-dimensional equation for steady uniform flows

When the flow is steady and uniform, $A, V$, and $D_{x}$ are independent of $x$ and $t . \quad E q 1$ is then simplified to:

$$
\frac{\partial C}{\partial t}=K_{2}\left(C_{s}-C\right)-K_{1} L+\alpha I-V \frac{\partial C}{\partial x}+D_{x} \frac{\partial^{2} C}{\partial x^{2}} \text {, }
$$

where $K_{2}$, the reaeration coefficient, is introduced to replace the quantity $K_{L} B / A$.

(iii) Steady-state equations and solutions

The customary step leading to steady-state equations has been to assume that the water temperature is constant so that $C_{S}$ remains constant. Introducing the dissolved oxygen deficit, $D=C_{s}-C$, and changing the dependent variable from $C$ to $D$, eq 2 is reduced to:

$$
\frac{\partial D}{\partial t}=-K_{2} D+K_{1} L-\alpha I-V \frac{\partial D}{\partial x}+D_{x} \frac{\partial^{2} D}{\partial x^{2}}
$$

For the steady-state condition, $\partial D / \partial t$ is zero and also the mixing term may be neglected relative to the convection term (Dobbins, 1964; Sayre and Chang, 1968), so that eq 3 is reduced to an ordinary differential equation

$$
-K_{2} D+K_{1} L-\alpha I-V \frac{d D}{d x}=0
$$


As for the variation of $L$, which represents $B O D$, a mass balance equation may similarly be derived as

$$
-\left(K_{1}+K_{3}\right) L-v \frac{d L}{d x}=0
$$

Analytical solutions to the coupled system, eq 4 and 5 , have been given by Dobbins (1964) and Camp (1965) as

$$
\begin{aligned}
D & =\frac{K_{1} L_{0}}{K_{2}-K_{1}-K_{3}} \exp \left(-\left(K_{1}+K_{3}\right) \frac{x}{V}\right)-\exp \left(-K_{2} \frac{x}{V}\right) \\
& -\frac{\alpha I}{K_{2}}\left(1-\exp \left(-K_{2} \frac{x}{V}\right)\right)+D_{0} \exp \left(-K_{2} \frac{x}{V}\right), \text { and } \\
L & =L_{o} \exp \left(-\left(K_{1}+K_{3}\right) \frac{x}{V}\right),
\end{aligned}
$$

where, $L_{O}$; BOD concentration at $x=0$,

$D_{0}$; oxygen deficit at $x=0$, and

$K_{3}$; rate coefficient for BOD removal due to nonbiological activities such as settling to the bed.

The steady-state solutions, eqs 6 and 7 , may be useful in simulating the well-known oxygen sag and recovery curve downstream from a point BOD source, provided that the values of four coefficients, $K_{1}, K_{2}, K_{3}$, and $\alpha$, are accurately predicted. Unfortunately, however, such prediction is not currently feasible for any of the coefficients, thus, most simulations by eqs 6 and 7 must rely on a trial-and-error optimization or calibration of the four coefficients. Transferability of these calibrated coefficients to other flows and situations is quite open to question (Peters and others 1980).

(iv) Time-dependent equations for a uniform and homogeneous reach

In order to obtain more concrete information on the processes of oxygen production and consumption than is available from eqs 6 and 7 , recent efforts have been directed to investigate a river reach, where the flow is hydraulically uniform and biologically homogeneous, so that the oxygen balance 
thereof is independent of location and dependent only on time (0'Connor and DiToro, 1970; Kelly and others 1974; Schurr and Ruchti, 1977).

Following Schurr and Ruchti (1977), assume that $K_{2}, K_{1} L$, and $\alpha$ are constant in eq 2 and introduce the definitions

$$
\begin{aligned}
C & =\langle C\rangle+C^{\prime}, \\
C_{s} & =\left\langle C_{s}\right\rangle+C_{s}^{\prime}, \text { and } \\
I & =\langle I\rangle+I^{\prime},
\end{aligned}
$$

where $\langle C\rangle,\left\langle C_{s}\right\rangle$, and $\langle I\rangle$ represent time averaged parts, and $C^{\prime}, C_{s}^{\prime}$ and $I^{\prime}$ represent time-dependent fluctuations or deviations from the averages. Substituting eqs 8,9 , and 10 into eq 2, the latter may be separated into the part representing the steady-state DO and the part representing the transient DO,

$$
\begin{aligned}
& K_{2}\left(\left\langleC_{s}>-\langle C>)-K_{1} L+\alpha\langle I\rangle-V \frac{\partial\langle C\rangle}{\partial x}+D_{x} \frac{\partial^{2}\langle C\rangle}{\partial x^{2}}=0 .\right.\right. \\
& \frac{\partial C^{\prime}}{\partial t}=K_{2}\left(C_{s}^{\prime}-C^{\prime}\right)+\alpha I^{\prime}-V \frac{\partial C^{\prime}}{\partial x}+D_{x} \frac{\partial^{2} C^{\prime}}{\partial x^{2}}
\end{aligned}
$$

Shurr and Ruchti (1977) stated that their formulation is restricted to a uniform flow, in which biological activities influencing DO and BOD are homogeneous so that not only $K_{2}, K_{1} L$, and $\alpha$ may be considered constant but also the convection term of eq 11 and the mixing term of eqs 11 and 12 are negligible. As for the convection term of eq 12, they mathematically analyzed the effect of areal variations of sun light intensity on solutions and concluded that this term is also negligible. However, their consideration was for the averaging period of over one month.

It appears that the above assumptions by Shurr and Ruchti are reasonable for some rivers and for a shorter period than one month. If the flow of the river of interest is reasonably steady and uniform for several days, one may be able to find a biologically homogeneous reach either upstream or far down- 
stream of a point BOD source. The information one obtains from such a reach on $K_{2}$ and $\alpha$ should also be applicable to the reach immediately downstream of the BOD source, provided that the flow remains uniform over these reaches.

There are a number of prototype observations to indicate that DO and water temperature in an ambient and homogeneous reach respond only to time-dependent driving forces of the sun light intensity. For example, Jackman and Yotsukura (1977) examined a set of natural water temperature data observed simulataneously at several stations along a $30 \mathrm{~km}$ reach of the Potomac River and concluded that the reach is thermally homogeneous, namely, that the natural water temperature in the reach is independent of location and varies only with time. Regarding the linear relationship of photosynthetic process assumed in eqs 11 and 12 , Mimura (written communication, 1979) conducted some experiments using a laboratory oxidation pond and confirmed the usefulness of this relationship in estimating the reaeration coefficient.

Based on these considerations, assume that $K_{2}, \alpha$, and $K_{1} L$ are all constant and the spatial gradient of Do $(\partial C / \partial x)$ is zero in eqs 11 and 12 , so that the simplified equations are:

$$
\begin{aligned}
& K_{2}\left(<C_{s}>-<C>\right)-K_{1} L+\alpha<I>=0 \\
& \frac{d C^{\prime}}{d t}=K_{2}\left(C_{s}^{\prime}-C^{\prime}\right)+\alpha I^{\prime}
\end{aligned}
$$

It is worthwhile to note that eqs 13 and 14, so far derived for a natural stream from the one-dimensional transport equation, could also be applied to a part of lakes, reservoirs, and estuaries, provided that the part is biologically homogeneous so that no spatial gradient of DO exists. For such water bodies, DO everywhere varies solely with time, with the sunlight intensity providing the major driving force for photosynthetic oxygen production. 
Eq 13 specifies the steady-state balance among the reaeration, BOD deoxygenation, and photosynthetic oxygen production processes. Eq 14, on the other hand, is an ordinary. differential equation specifying the timedependent DO variations which are controlled by reaeration and photosynthesis. In solving eq 14, the following Fourier series forms are assumed for $C^{\prime}$ and for the two driving terms, $I^{\prime}$ and $C_{S}^{\prime}$

$$
\begin{aligned}
C^{\prime} & =\sum_{n=1}^{\infty} A_{n} \cos \left(\Omega_{n} t\right)+\sum_{n=1}^{\infty} B_{n} \sin \left(\Omega_{n} t\right) \\
& =\sum_{n=1}^{\infty} C_{n} \cos \left(\Omega_{n} t-T_{n}\right), \\
C_{s}^{\prime} & =\sum_{n=1}^{\infty} D_{n} \cos \left(\Omega_{n} t-S_{n}\right), \\
I^{\prime} & =\sum_{n=1}^{\infty} J_{n} \cos \left(\Omega_{n} t\right), \text { and } \\
\Omega_{n} & =\frac{2 n \pi}{24}(n=1,2,3, \ldots),
\end{aligned}
$$

where, $C_{n}$; a Fourier coefficient of the nth harmonic component of DO, $T_{n}$; a phase shift between the sun light intensity and DO of the nth harmonic component in radians,

$D_{n}$; a Fourier coefficient of the nth harmonic component of saturation concentration of DO,

$S_{n}$; a phase shift between the sun light intensity and saturation concentration of $\mathrm{DO}$ of the nth harmonic component in radians,

$J_{n}$; a Fourier coefficient of the nth harmonic component of the sun light intensity,

$\Omega_{n}$; the nth angular frequency in radians $\mathrm{hr}^{-1}$, corresponding to the nth period, $p_{n}=24 / n$ in hours,

$n$; integer index for the angular frequency and period, and

$t$; time in hours. 
Solution for $C^{-}$is obtained by substituting eqs 15, 16, 17, and 18 into eq 14 and determining the coefficient $C_{n}$ and the phase shift $T_{n}$. The solution also should satisfy proper initial conditions if necessary.

(v) Previous solutions of eq 14

Schurr and Ruchti (1977) solved eq 14 under the condition of $C_{s}^{\prime}=0$, assuming that the water temperature variation was less than $0.5^{\circ} \mathrm{C}$. Substituting eqs 15, 17, and 18 into eq 14, they obtained the following relationship

$$
\begin{aligned}
K_{2} & =\frac{\Omega_{n}}{\tan \left(T_{n}\right)}, \text { and } \\
\alpha & =\frac{K_{2} C_{n}}{J_{n} \cos \left(T_{n}\right)} .
\end{aligned}
$$

Note that eqs 19 and 20 are given in terms of one component of various Fourier series defined in eqs 15 through 18. These theoretical forms, which accomodate potential contributions of various frequencies $(n=1,2,3, \ldots)$, will be retained, despite the physical situation that suggests that the dominent contribution to $C^{\prime}$ variation will mostly come from diurnal variations of $I^{\prime}$, corresponding to $\Omega_{1}=2 \pi / 24$ radians $\mathrm{hr}^{-1}$ or $p_{1}=24$ hours.

In applying the above model, Schurr and Ruchti (1977) proposed the use of time series data of DO obtained at a single point in a river. By means of the cross-correlation analysis of the DO and idealized sun light intensity data obtained for a Swiss stream, they determined the phase shift, $T_{n}$, the DO coefficient, $C_{n}$, the sun light intensity coefficient, $J_{n}$, and average values, $\langle C\rangle$ and $\langle I\rangle$. The reaeration coefficient, $K_{2}$, the photosynthetic coefficient, $\alpha$, and the deoxygenation rate of BOD were then calculated from eqs 19, 20, and 13 respectively. When they compared the results obtained by the consideration 
of the single frequency component $(n=1)$ with those by the two frequency components $(n=1$ and 2), however, they found that the results are very similar, provided that the data conforms with the assumption of uniform and homogeneous flows.

AN APPLICATION OF THE SPECTRAL ANALYSIS METHOD

\section{(i) Recapitulation}

The original method proposed by Schurr and Ruchti (1977) was based on the conditions that, 1$)$ the steady-state coefficients such as $K_{2}, \alpha$, and $K_{1} L$ are averaged values over a one-month period, 2) the diurnal variation of water temperature is less than $0.5^{\circ} \mathrm{C}$ so that $C_{s}$ remains constant, and 3) the cross-correlation method is used for data analysis. In many natural streams, the river discharge rarely remains steady for a one-month period. In order to apply the method to more common situations, it is desirable to use data from a river in which the flow is steady for 3 to 7 days. The crosscorrelation analysis normally requires a time-series data of at least 10-days duration and, moreover, the accuracy of estimating the phase shift, $T_{n}$, is determined by the magnitude of the time interval of the data. In fact, Schurr and Ruchti used a time interval of 12 minutes throughout 8-days data. In view of these practical limitations of the original method, the present method proposes to 1) incorporate the variability of $C_{S}^{\prime}$ into the solution of eq 14 , and 2) replace the cross-correlation method by the more efficient spectral analysis method (Jenkins and Watts, 1968).

(ii) Revised solutions of eq 14

When the time-dependent variation for $C_{s}^{\prime}$ is assumed as shown in eq 16 , the corresponding solutions to eq 14 are given by

$$
K_{2}=\frac{C_{n} \Omega_{n} \cos \left(T_{n}\right)}{C_{n} \sin \left(T_{n}\right)-D_{n} \sin \left(S_{n}\right)} \text {, and }
$$




$$
\alpha=\frac{K_{2}\left(C_{n}-D_{n} \cos \left(T_{n}-S_{n}\right)\right)}{J_{n} \cos \left(T_{n}\right)}
$$

Note that eqs 19 and 20 are special cases of eq 21 and 22 with $D_{n}=0$. Derivation of eqs 21 and 22 are explained in the Supplementary Information at the end of the text. Eq 13, which is needed for the calculation of $K_{1} L$, is restated here

$$
K_{1} L=K_{2}\left(\left\langleC_{s}>-\langle C>)+\alpha<I>\right.\right.
$$

Eqs 21,22 , and 13 , constitute the set of revised solutions from which $K_{2}$, $\alpha$, and $K_{1} L$ are to be calculated sequentially by use of time series data. (iii) Application of the spectral analysis method Theoretically, the time fluctuation of DO is influenced by various component fluctuations, such as high frequency components present in the turbulence of stream flow, regular diurnal variations in the sun light intensity and its higher-order harmonics, diurnal fluctuations in water temperature, diurnal and weekly variations in man-made activities, seasonal and/or yearly variations in the sun light intensity, water temperature, and stream discharge. The spectral analysis in the frequency domain gives a clear and convenient means of calculating statistical properties of the data, particularly with respect to periodic phenomena (Jenkins and Watts, 1968).

Figures 1, 2, and 3 show three typical patterns of power spectral density for the DO obtained from data of the Cuyahoga River, Ohio, 1976. The abscissa of these figures designates the angular frequency, $\Omega_{n}=2 \pi / p_{n}$, where $p_{n}=24 / n$ is the period in hours and $n$ is the integer index for frequency and period. The ordinate of the figures indicates the portion of the total variance of DO attributable to a particular frequency or period. In figure 1, the variance is almost exclusively concentrated in the single frequency, $\Omega_{1}=2 \pi / 24$, corresponding to the period of 24 hours. In figure 2, the variance is distributed among several frequencies, namely, 0.524, 0.262, and those less 


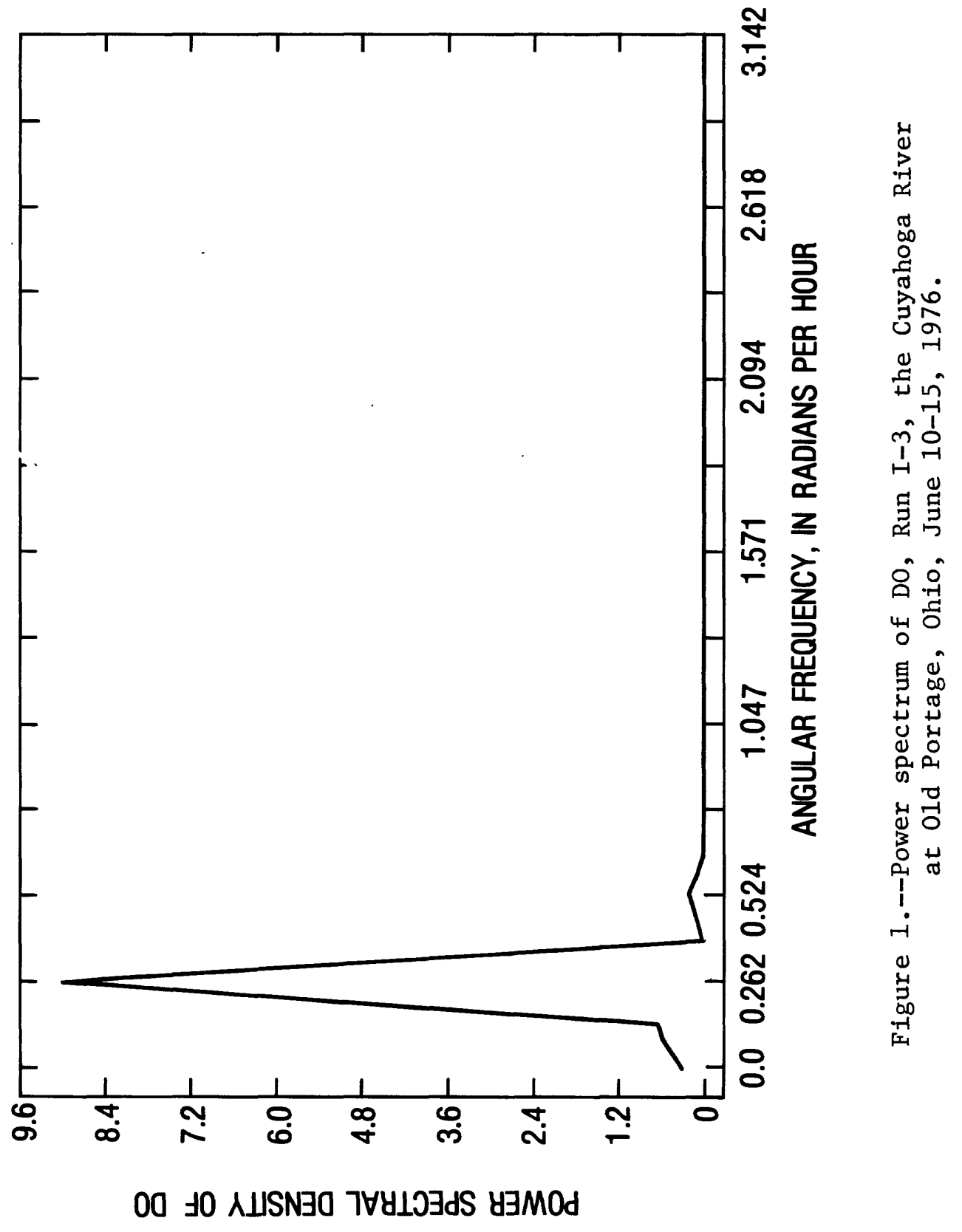




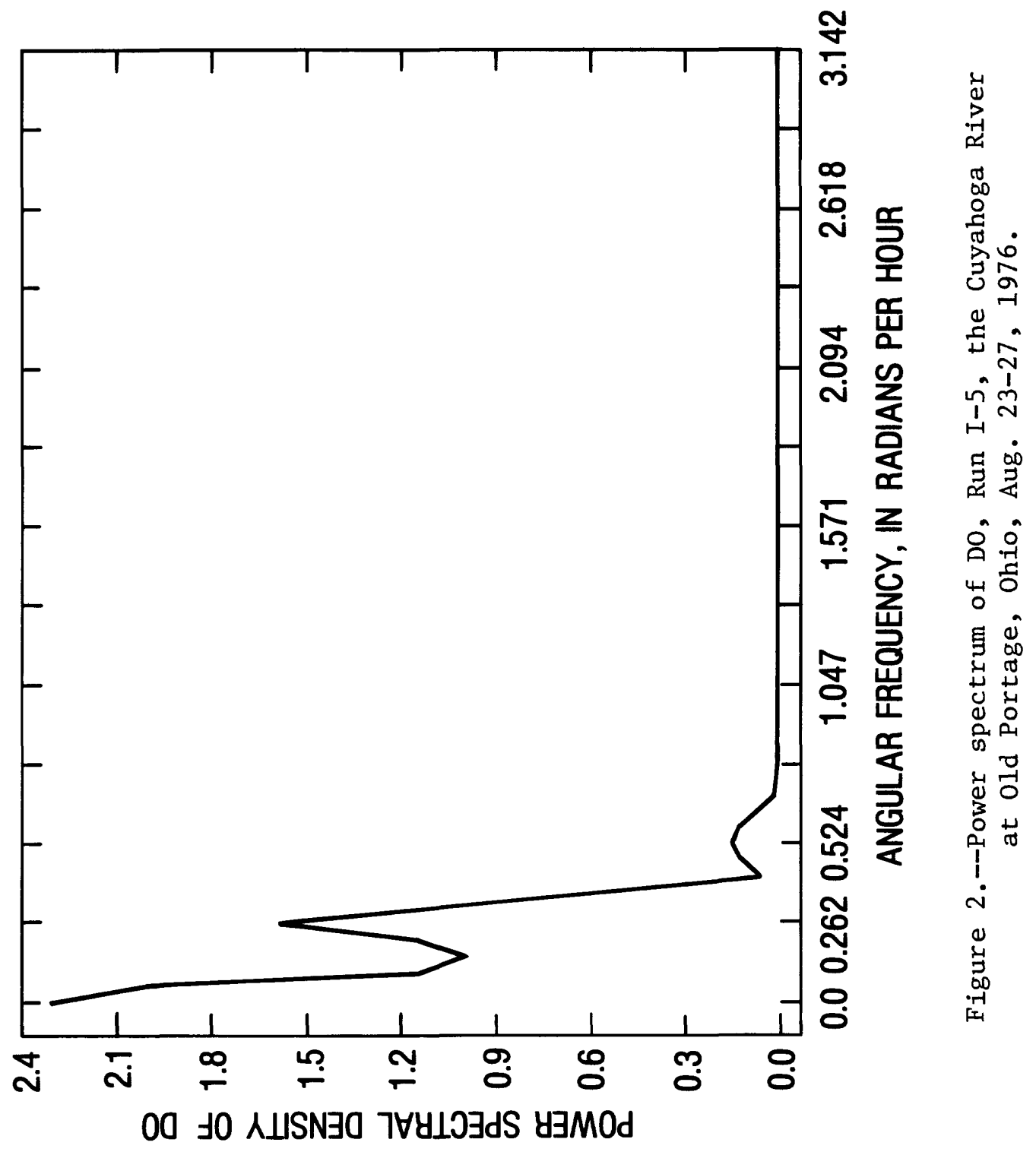




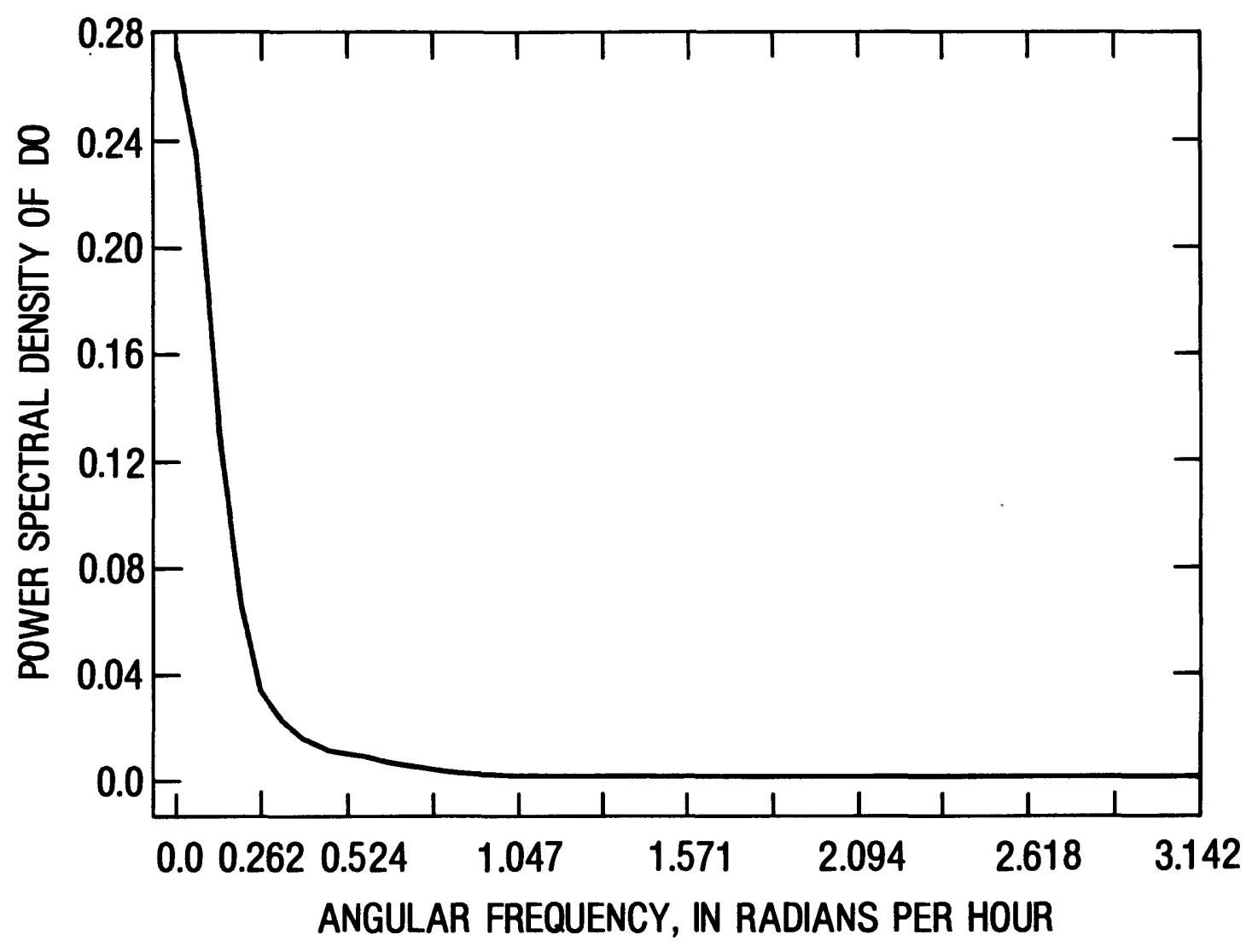

Figure 3.--Power spectrum of DO, Run II-3, the Cuyahoga River at Independence, Ohio, July 16-19, 1976. 
than 0.262. In figure 3, a majority of the total variance is concentrated in frequencies less than 0.262 or periods larger than 24 hours. It is thus clear that the proposed model, eqs 13 and 14, is ideally suited to the data of figure 1. On the other hand, one must be cautious in applying the model for data shown in figures 2 and 3.

Figures 4, 5, and 6 show three patterns of power spectral density for water temperature measured at the same location and during the same period as figures 1, 2, and 3, respectively. The spectral curves of figures 4, 5, and 6 are generally similar to those of figures 1, 2, and 3, respectively, indicating the predominant influence of the same periodicities on DO and natural water temperatures. These data were obtained with a uniform time interval of 1 hour and a duration of 3 to 5 days, for which the river discharge was observed to be steady.

(iv) Field data of the Cuyahoga River in Ohio.

Water quality data have been collected by the Ohio District of the U.S. Geological Survey as part of their routine water quality monitoring activities at two observation stations of the Cuyahoga River located at 01d Portage and Independence, Ohio. The identifier, latitude, and longitude for these stations are tabulated in table 1. For the years 1976 and 1977, typical variations of the DO, the saturation concentration of DO, and the river discharge measured at these stations are displayed in figures 7,8 , and 9.

Regarding the sun 1ight intensity, the Ohio District did not have any measured information, so a theoretical sun light intensity function was used. The sun light function at the two specific locations along the Cuyahoga River is expressed by eq 23 and intensities are also shown in figures 7 , 8, and 9. 


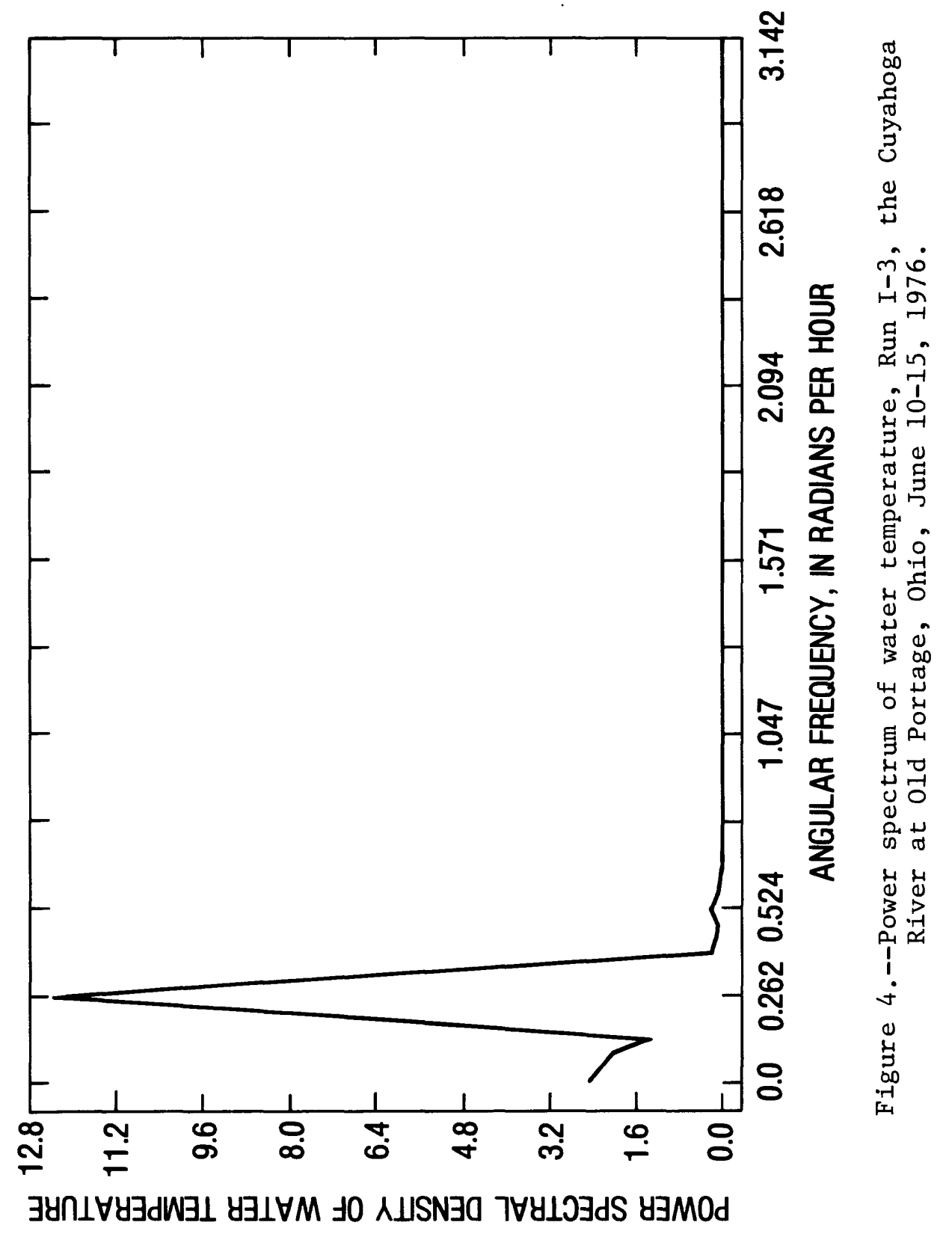




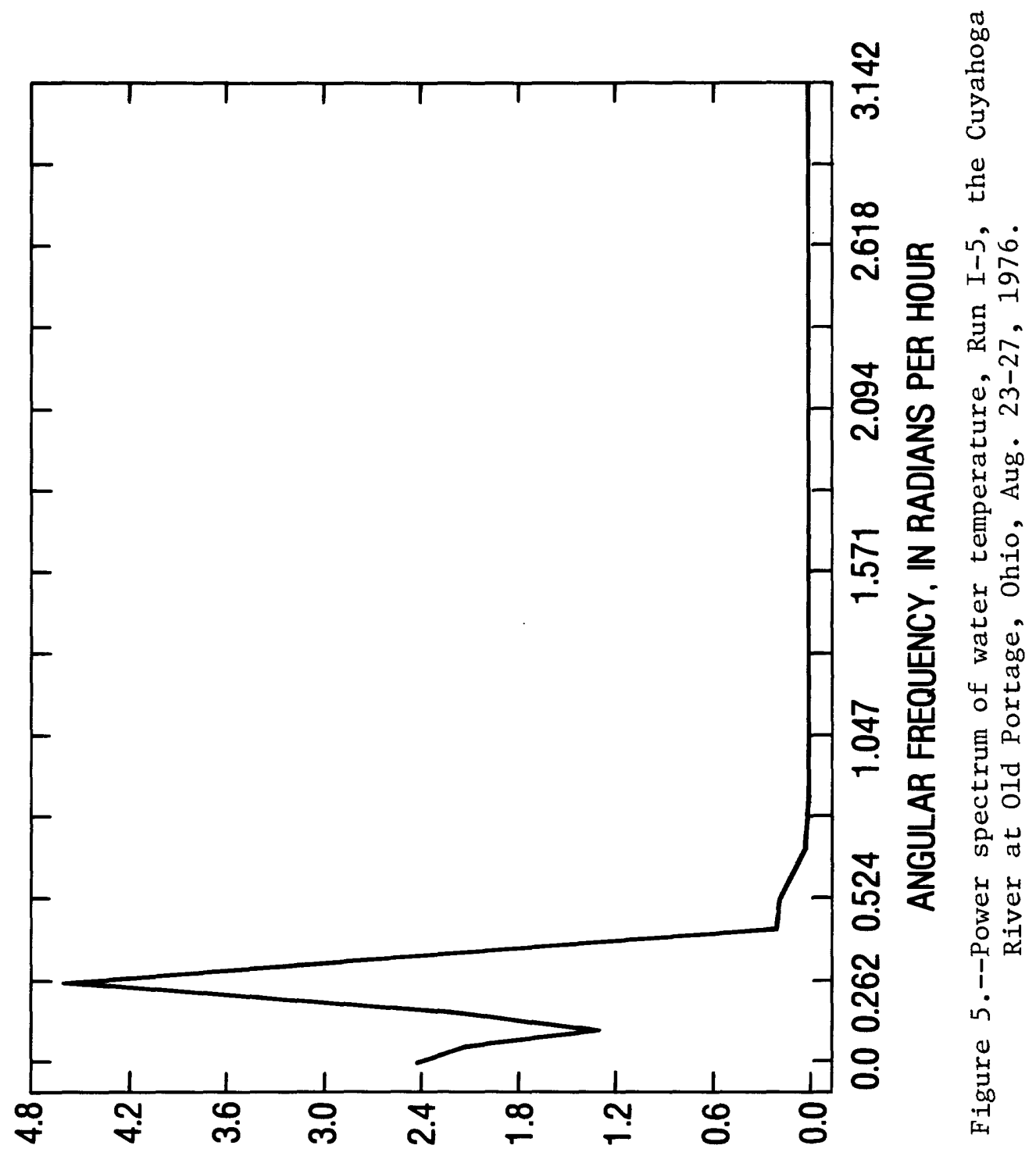

$\exists \forall \cap \perp \forall y \exists d W \exists \perp \forall \exists \perp \forall M \quad J 0 \wedge \perp I S N \exists O 7 \forall \forall \perp 0 \exists d S$ y $\exists M O d$ 


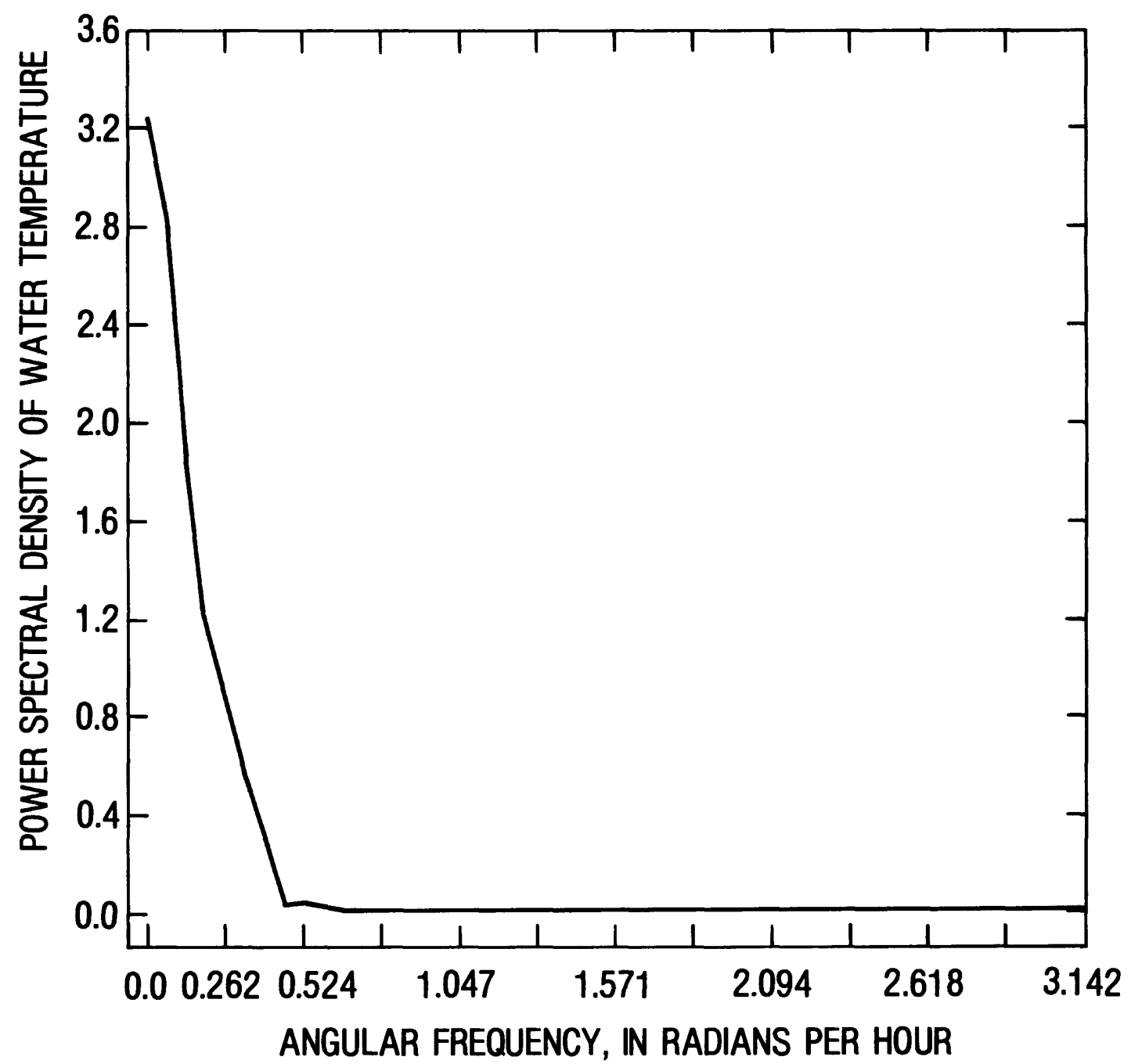

Figure 6.--Power spectrum of water temperature, Run II-3, the Cuyahoga River at Independence, Ohio, July 16-19, 1976. 
Table 1. Description of observation stations, the Cuyahoga River, Ohio

\begin{tabular}{|c|c|c|c|}
\hline Station identifier & Station name & Latitude & Longitude \\
\hline 04206000 & Old Portage, Ohio & $41^{\circ} 08^{\prime} 08^{\prime \prime}$ & $81^{\circ} 31^{\prime} 51^{\prime \prime}$ \\
\hline 04208000 & Independence, Ohio & $41^{\circ} 23^{\prime} 43^{\prime \prime}$ & $81^{\circ} 37^{\prime} 48^{\prime \prime}$ \\
\hline
\end{tabular}



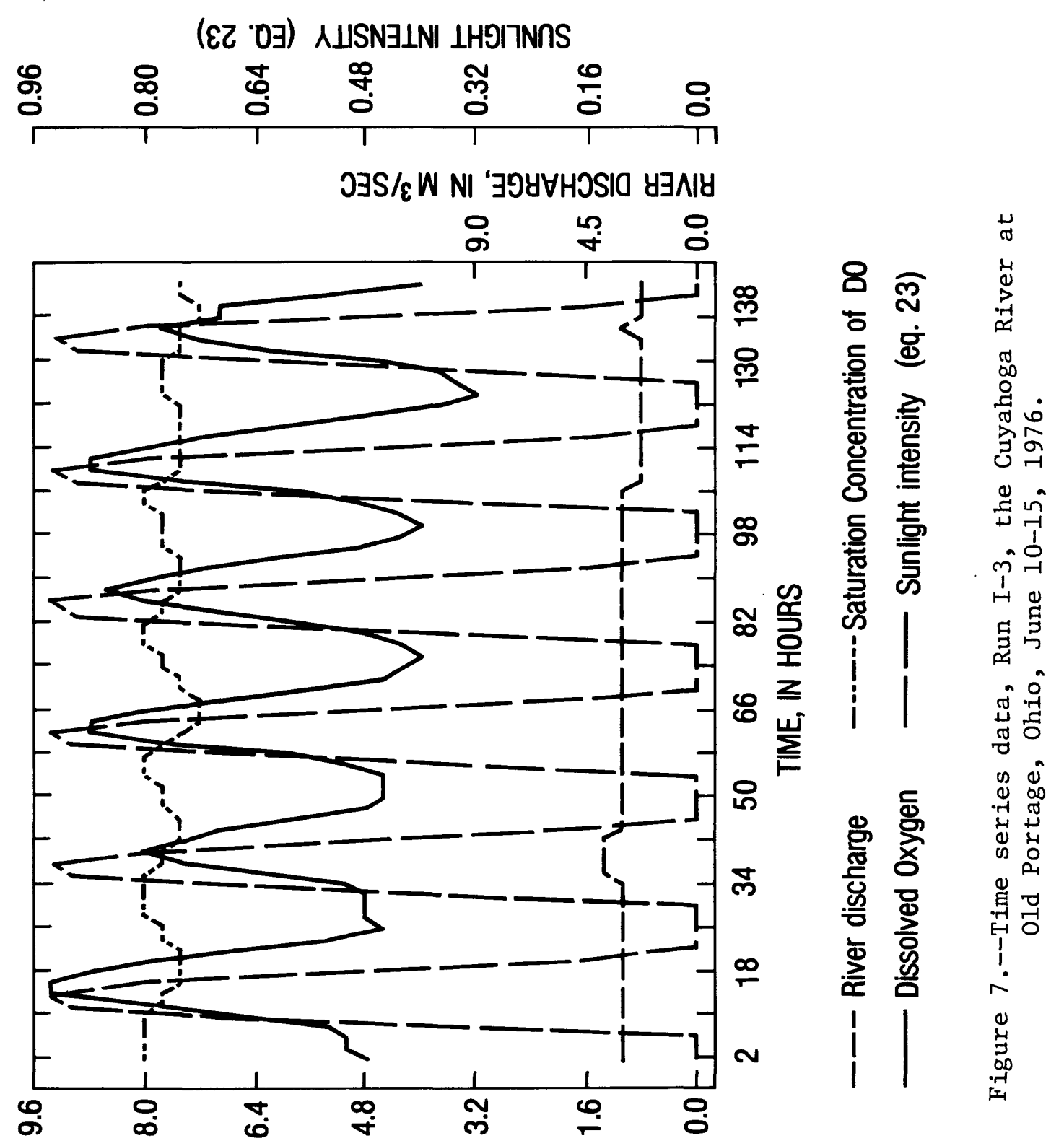

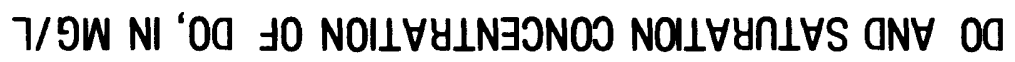




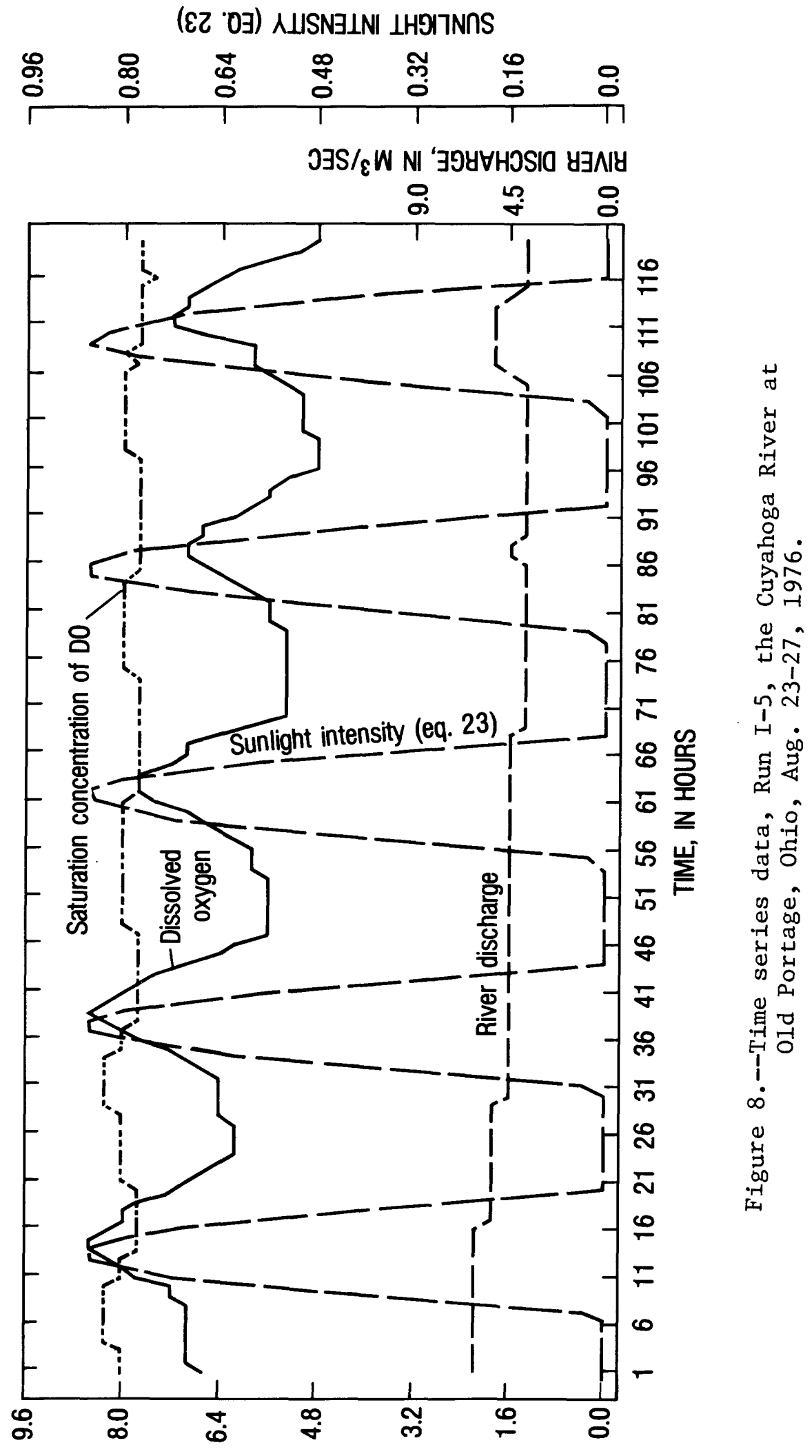

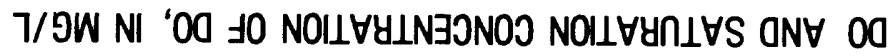



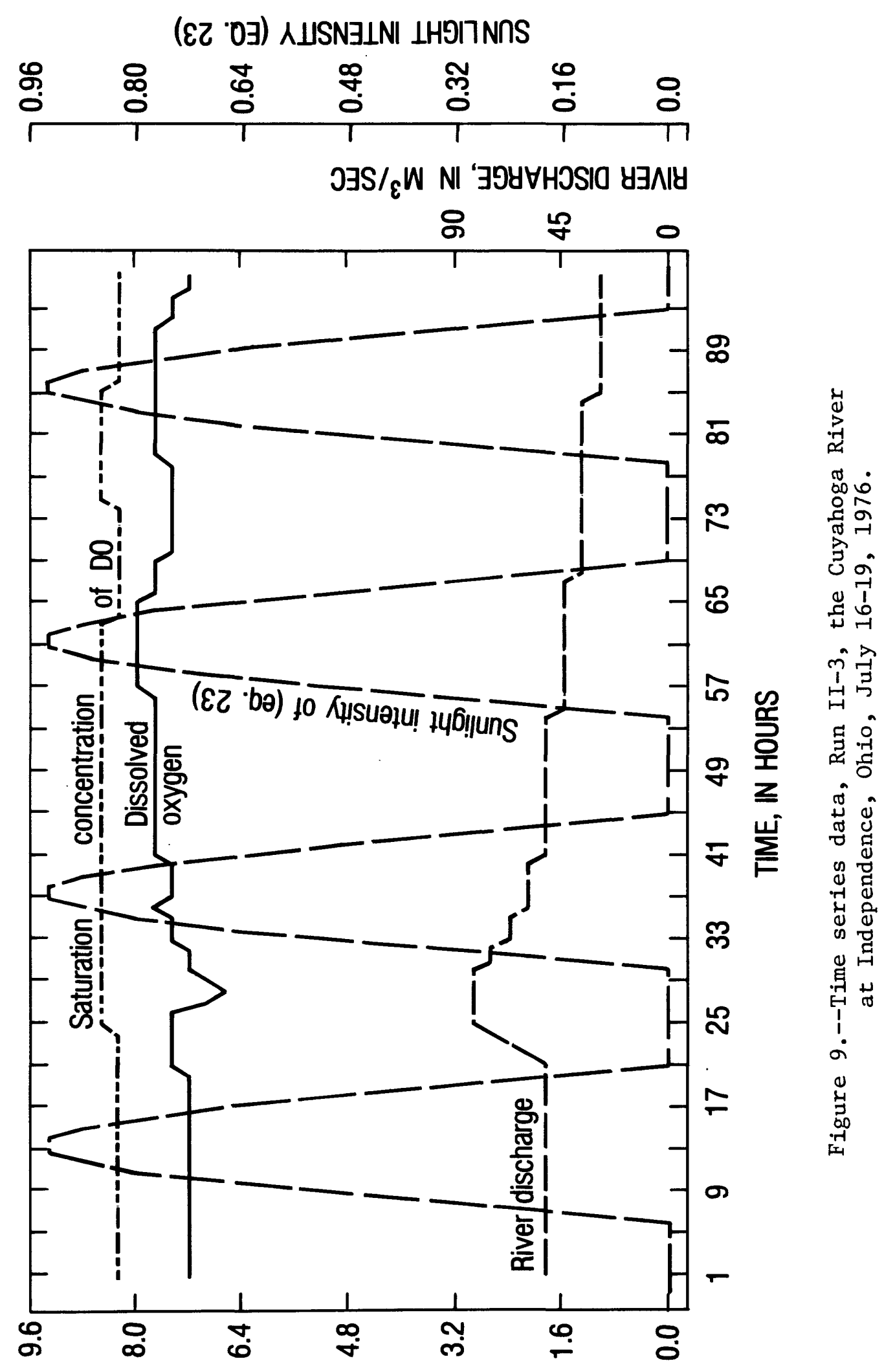

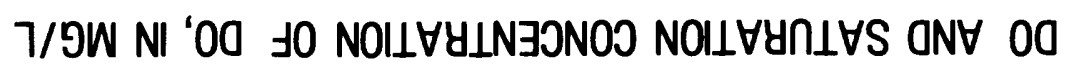




$$
\begin{aligned}
I^{\prime}= & \sin \phi \sin \rho+\cos \phi \cos \rho \cos \left\{\omega\left(t+\tau_{1}+\tau_{2}-12\right)\right\} \\
& \quad \text { or } t_{1} \leq t \leq t_{2} \\
I^{\prime}= & 0, \text { for } 0 \leq t<t_{1} \text { and } t_{2}<t \leq 24
\end{aligned}
$$

where, $t$; local time in hours,

$t_{1}$; the time of sunrise,

$t_{2}$; the time of sunset,

$\tau_{1}$; a correction factor for the difference of the longitude between the standard longitude of local time and that of the observation station,

$\tau_{2}$; a correction factor for the daylight-saving time, namely, $\tau_{2}=0$ in winter and $\tau_{2}=1$ in summer,

$\phi$; latitude of the observation station,

$\rho$; the solar declination, and

$\omega$; the angular velocity of rotation of the earth, $\omega=2 \pi / 24$.

(v) Results of calculations for the Cuyahoga River

A number of data sets were selected from the data of 1976 and 1977 for the condition of stationarity of the river discharge for a duration of 3 to 6 days. Spectral analyses were applied for DO, sun light intensity, and saturation concentration of DO determined from the water temperature, by use of the SPECTRA procedure and the triangular weighting technique, WEIGTHS 12321, of the SAS System (Barr and others 1976). The scheme utilizes the Fast Fourier Transform and is believed to be one of the most efficient computational schemes.

Computed power spectra, coherencies, and phase spectra for a typical data set are presented in figure 1 and figures 10 to 13. From such data analyses, it became clear that the only dominant periodicity for the Cuyahoga River during the period considered was the 24-hour periodicity. Thus equation 21 was simplified to represent $n=1$ only, or 


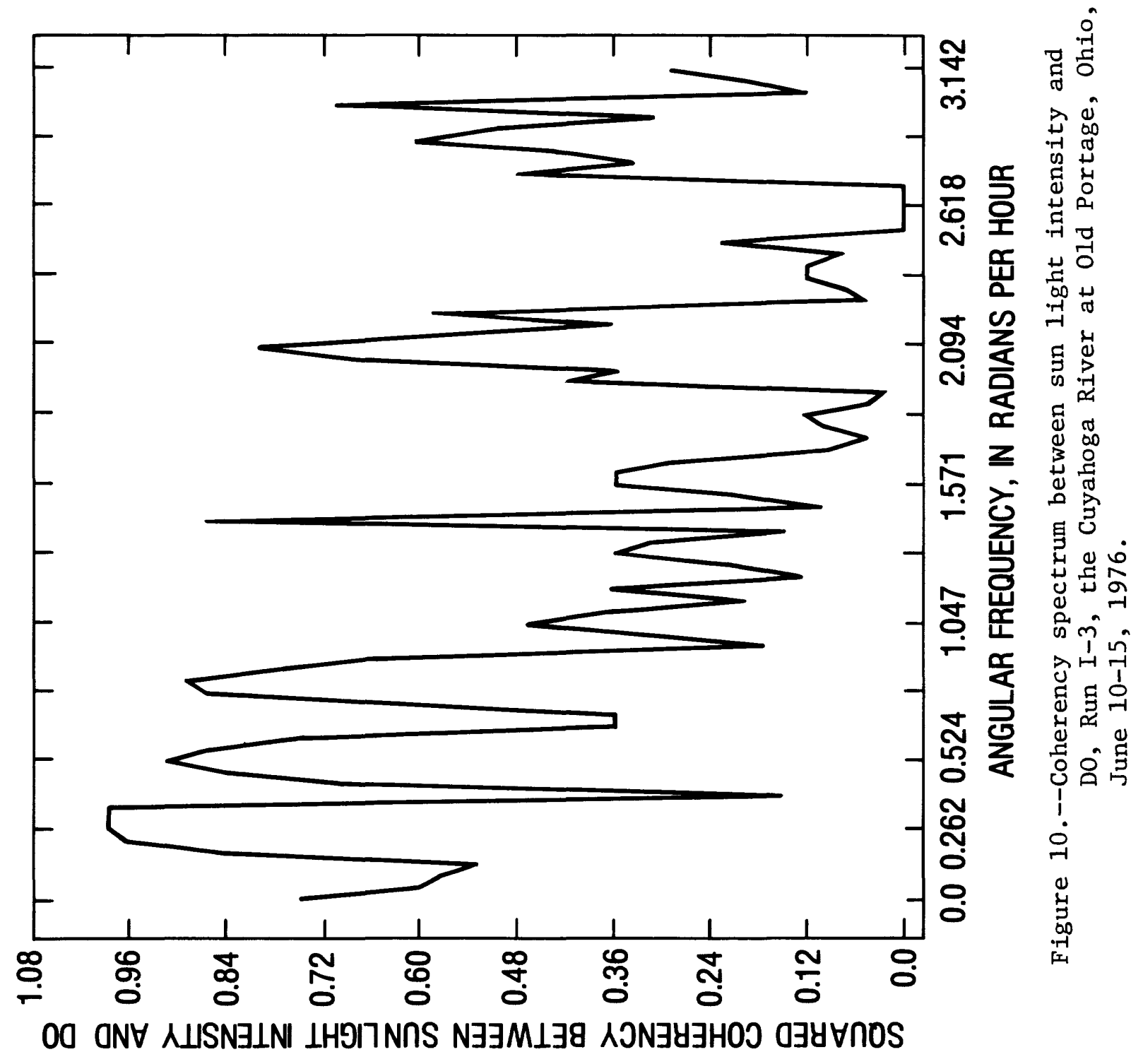




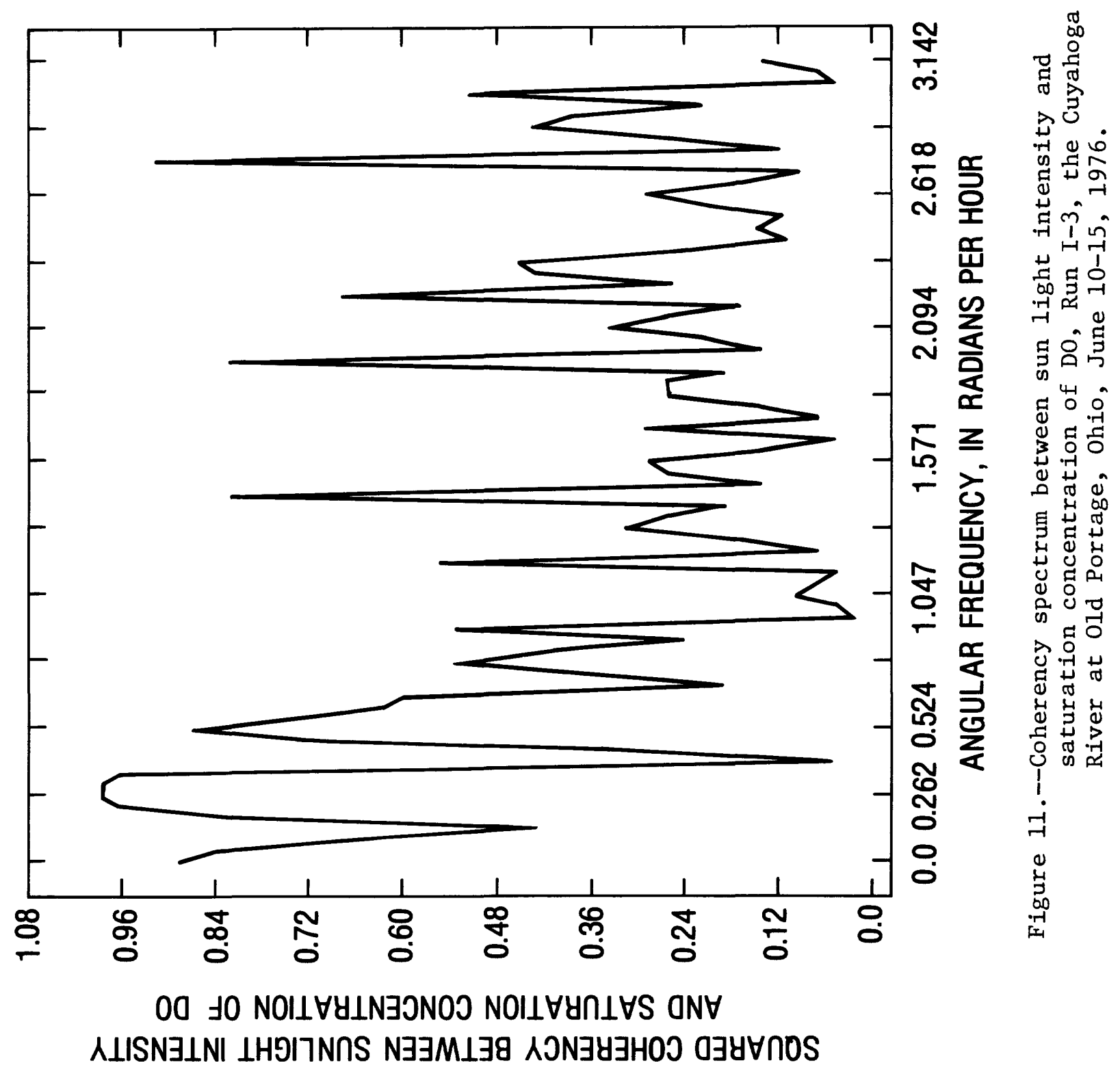




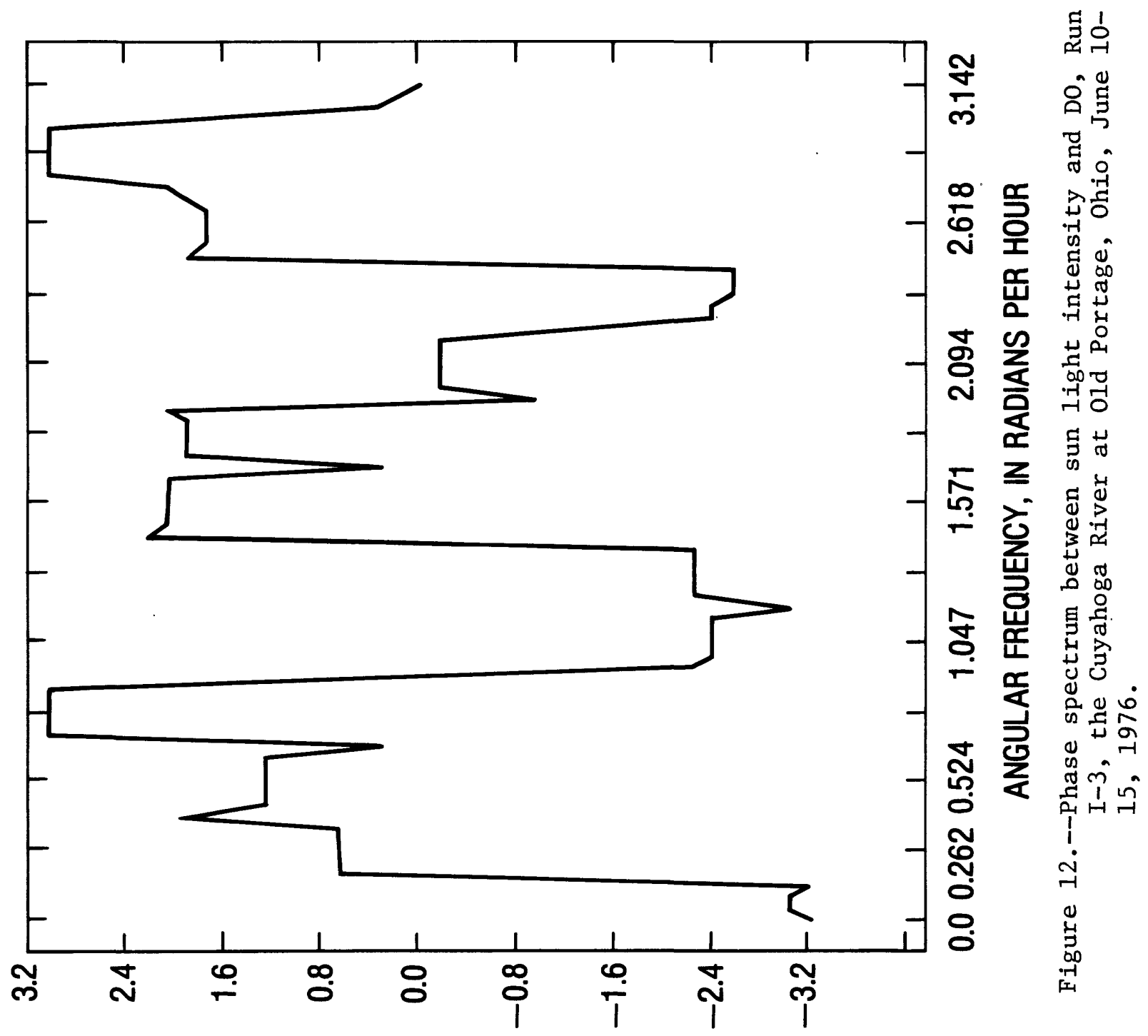

SN 


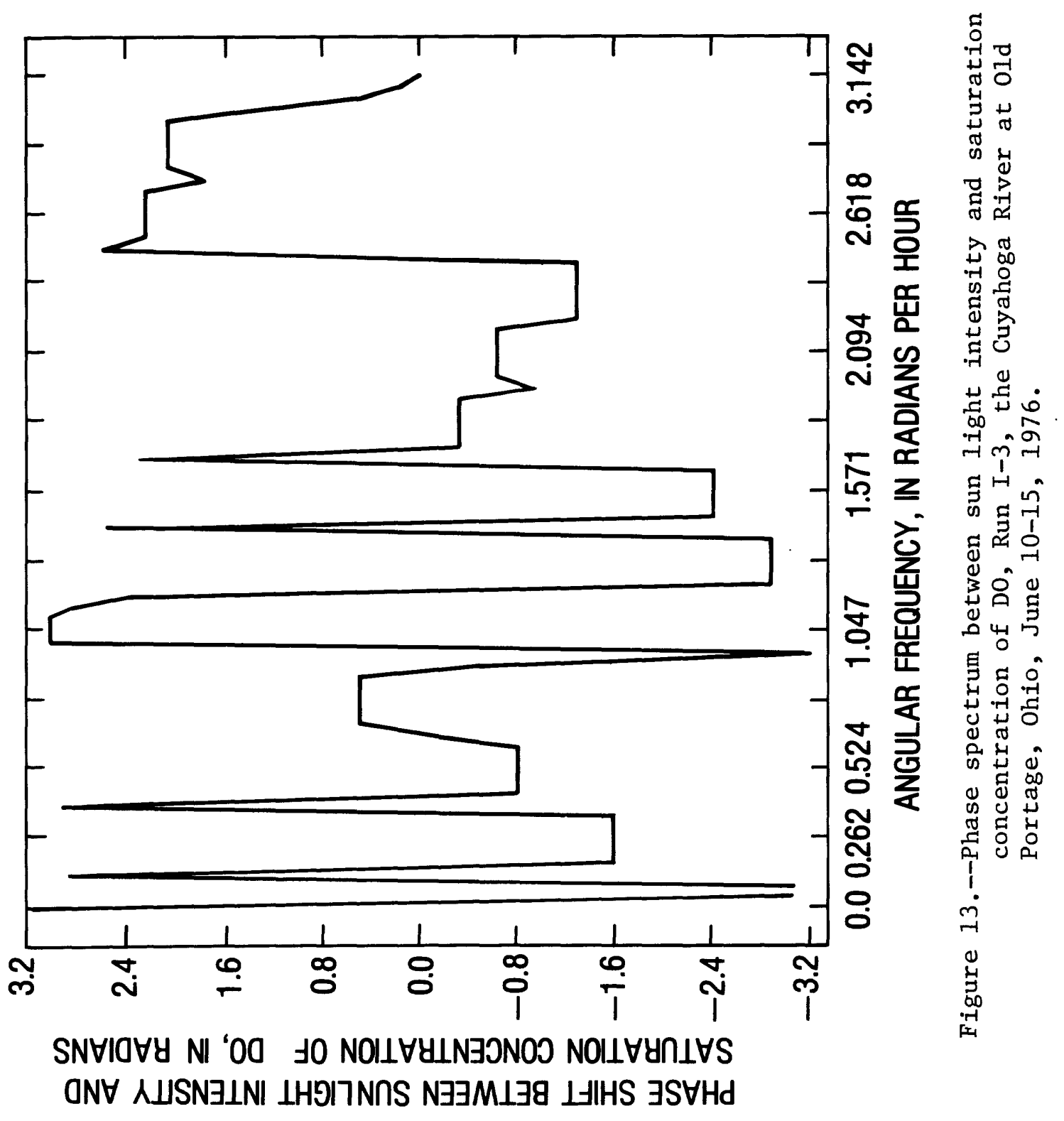




$$
K_{2}=\frac{C_{1} \cdot \frac{2 \pi}{24} \cdot \cos \left(T_{1}\right)}{C_{1} \sin \left(T_{1}\right)-D_{1} \sin \left(S_{1}\right)}
$$

The correction of the reaeration coefficients for the effect of temperature was done by the formula of Elmore and West (1961),

$$
\left(K_{2}\right)_{20}=\left(K_{2}\right)_{T} \cdot \theta^{(20-T)}
$$

where $T$ is water temperature in degrees Celsius, and $\theta=1.0241$. Because of the preliminary nature of this study, the photosynthetic production rate, $\alpha$, and the deoxygenation rate, $K_{1} L$, where not examined. Observed data for river discharge and water temperature, and the calculated parameters and estimated $K_{2}$ values, are summarized in table 2 .

\section{DISCUSSION OF THE SPECTRAL METHOD}

\section{(i) Consistency between data and model}

The analytical model encompassing eqs 13 through 24 is based on the assumption that the reach is hydraulically uniform and biologically homogeneous with respect to activities influencing DO and BOD. In prototype rivers, however, the aggregate information such as discharge, channel geometries, and point BOD sources often does not suffice to guarantee the homogeneity of a stream reach. In order to obtain a check on the consistency between the model and the data, one must carefully examine statistical parameters calculated from data. For example, Run Number II-3 in table 2 shows that $C_{1}$, the amplitude of the 24hour Fourier component, is only 0.183 and indicates the insignificance of the 24-hour periodicity as shown earlier in figure 3. Thus the value of $K_{2}$ calculated by means of eq 24 for this run may not be physically meaningful, however reasonable the numerical value of $K_{2}$ may appear in table 2. Even though the spectral analysis is believed to provide a viable means of checking the consistency between model and data, the following procedure is still preliminary and is not meant to cover all conditions to be expected in prototype rivers. 
Table 2-I.--Summary of data and computations, the Cuyahoga River at old Portage, Ohio

\begin{tabular}{|c|c|c|c|c|c|c|c|c|c|c|c|c|}
\hline \multirow{2}{*}{$\begin{array}{l}\text { Run } \\
\text { No. }\end{array}$} & \multicolumn{3}{|c|}{ Time } & \multicolumn{3}{|c|}{$\begin{array}{c}\text { Discharge } \\
\text { in } \mathrm{m}^{3} \mathrm{~s}^{-1}\end{array}$} & \multicolumn{3}{|c|}{$\begin{array}{c}\text { Water Temp. } \\
\text { in }{ }^{\circ} \mathrm{C}\end{array}$} & \multicolumn{3}{|c|}{$\begin{array}{c}\text { DO } \\
\text { in mg liter }\end{array}$} \\
\hline & Days & Month & Year & Mean & $\operatorname{Max}$ & Min & Mean & $\operatorname{Max}$ & Min & Mean & $\operatorname{Max}$ & Min \\
\hline$I-1$ & $23-27$ & Dec. & 1975 & 12.2 & 17.1 & 9.4 & 2.7 & 3.8 & 1.7 & 11.8 & 12.4 & 11.4 \\
\hline$I-2$ & $4-9$ & May & 1976 & 9.1 & 12.0 & 7.7 & 16.7 & 19.9 & 14.0 & 9.3 & 12.3 & 7.1 \\
\hline$I-3$ & $10-15$ & June & 1976 & 2.9 & 3.8 & 2.4 & 27.9 & 31.9 & 24.4 & 6.1 & 9.4 & 3.3 \\
\hline$I-4$ & $26-28$ & July & 1976 & 6.6 & 7.6 & 5.2 & 25.6 & 29.6 & 21.9 & 6.8 & 7.9 & 5.3 \\
\hline$I-5$ & $23-27$ & Aug. & 1976 & 4.6 & 6.2 & 3.7 & 25.9 & 28.4 & 23.2 & 6.4 & 8.4 & 4.7 \\
\hline$I-6$ & $2-6$ & Sept. & 1976 & 3.6 & 4.2 & 3.2 & 22.8 & 25.9 & 19.1 & 5.9 & 8.0 & 3.7 \\
\hline I-7 & $21-24$ & Sept. & 1976 & 23.4 & 26.8 & 18.6 & 18.1 & 20.0 & 16.7 & 8.0 & 8.6 & 7.3 \\
\hline$I-8$ & $26-29$ & May & 1977 & 2.9 & 3.2 & 2.8 & 25.5 & 29.6 & 21.7 & 5.6 & 9.5 & 3.0 \\
\hline I-9 & $13-15$ & July & 1977 & 5.3 & 6.5 & 4.2 & 29.6 & - & - & 1.4 & 3.4 & 0.2 \\
\hline
\end{tabular}

\begin{tabular}{|c|c|c|c|c|c|c|}
\hline $\begin{array}{c}\text { Run } \\
\text { No. }\end{array}$ & $\begin{array}{c}\text { Amp1itude } \\
\mathrm{C}_{1} \text { (Eq. 15) } \\
\text { in liter }\end{array}$ & $\begin{array}{c}\text { Amplitude } \\
\mathrm{D}_{1} \text { (Eq. 16) } \\
\text { in } \\
\text { mg liter }\end{array}$ & $\begin{array}{c}\text { Phase } \\
\text { Shift T } \\
\text { (Eq. 15) } \\
\text { in radians }\end{array}$ & $\begin{array}{c}\text { Phase } \\
\text { Shift S } \\
\text { (Eq. 16) } \\
\text { in radians }\end{array}$ & $\begin{array}{c}\text { Reaeration } \\
\text { Coefficient } \\
\text { in hr }\end{array}$ & $\begin{array}{c}\text { Reaeration } \\
\text { Coefficient } \\
\text { at } \\
\text { in day }\end{array}$ \\
\hline I-1 & 0.225 & 0.116 & 0.365 & 0.434 & $1.48 *$ & $53.5 *$ \\
I-2 & 2.07 & .415 & .422 & -2.088 & 0.409 & 10.61 \\
I-3 & 3.01 & .415 & .701 & -1.618 & 0.255 & 5.06 \\
I-4 & 0.804 & .319 & .312 & -1.859 & 0.362 & 7.61 \\
I-5 & 1.26 & .254 & .402 & -1.799 & 0.416 & 8.54 \\
I-6 & 1.51 & .386 & .412 & -1.716 & 0.367 & 8.23 \\
I-7 & 0.274 & .077 & .006 & -2.985 & $5.23 *$ & $131.3 *$ \\
I-8 & 2.91 & .444 & .596 & -1.559 & 0.303 & 6.36 \\
I-9 & 1.17 & .339 & -0.055 & -1.890 & $-*$ & $-*$ \\
\hline
\end{tabular}

* Refer to page 34 of the text. 
Table 2-II.--Summary of data and computations,

the Cuyahoga River at Independence, Ohio

\begin{tabular}{|c|c|c|c|c|c|c|c|c|c|c|c|c|}
\hline \multirow{2}{*}{$\begin{array}{l}\text { Run } \\
\text { No. }\end{array}$} & \multicolumn{3}{|c|}{ Time } & \multicolumn{3}{|c|}{$\begin{array}{c}\text { Discharge } \\
\text { in } \mathrm{m}^{3} \mathrm{~s}^{-1}\end{array}$} & \multicolumn{3}{|c|}{$\begin{array}{c}\text { Water Temp. } \\
\text { in }{ }^{\circ} \mathrm{C}\end{array}$} & \multicolumn{3}{|c|}{$\begin{array}{c}\text { DO } \\
\text { in mg 1iter } \\
-1\end{array}$} \\
\hline & Days & Month & Year & Mean & $\operatorname{Max}$ & Min & Mean & $\operatorname{Max}$ & Min & Mean & Max & Min \\
\hline II-I & $9-12$ & April & 1976 & 22.4 & 26.3 & 19.5 & 10.0 & 12.2 & 7.2 & 9.1 & 10.0 & 8.2 \\
\hline II-2 & $10-15$ & June & 1976 & 5.5 & 7.4 & 3.9 & 24.8 & 26.9 & 22.2 & 7.0 & 10.1 & 5.0 \\
\hline II-3 & $16-19$ & July & 1976 & 49.8 & 85.0 & 31.2 & 22.0 & 23.7 & 20.1 & 7.5 & 7.9 & 6.7 \\
\hline II-4 & $23-27$ & Aug. & 1976 & 7.1 & 9.8 & 5.5 & 23.1 & 24.4 & 21.8 & 7.6 & 10.1 & 5.8 \\
\hline$I I-5$ & $2-6$ & Sept. & 1976 & 5.6 & 6.7 & 4.2 & 19.3 & 21.0 & 16.6 & 7.7 & 9.4 & 6.7 \\
\hline II- 6 & $16-19$ & May & 1977 & 8.0 & 9.0 & 6.8 & 21.3 & 24.5 & 17.7 & 6.0 & 8.6 & 3.9 \\
\hline II-7 & $20-23$ & May & 1977 & 7.0 & 8.5 & 6.0 & 23.8 & 25.9 & 21.4 & 6.0 & 9.9 & 3.4 \\
\hline II-8 & $26-19$ & May & 1977 & 5.7 & 8.3 & 4.2 & 22.6 & 24.7 & 20.1 & 5.6 & 7.5 & 3.0 \\
\hline II-9 & $29-31$ & May & 1977 & 4.6 & 5.4 & 3.9 & 21.8 & 23.8 & 20.0 & 5.7 & 8.3 & 3.0 \\
\hline
\end{tabular}

\begin{tabular}{|c|c|c|c|c|c|c|}
\hline $\begin{array}{l}\text { Run } \\
\text { No. }\end{array}$ & $\begin{array}{l}\text { Amplitude } \\
\mathrm{C}_{1} \text { (Eq. 15) } \\
\text { in } \\
\text { mg 1iter }\end{array}$ & $\begin{array}{l}\text { Amplitude } \\
\mathrm{D}_{1} \text { (Eq. 16) } \\
\text { in } \\
\mathrm{mg} 1 \text { iter }^{-1}\end{array}$ & $\begin{array}{l}\text { Phase } \\
\text { Shift } \mathrm{T}_{1} \\
\text { (Eq. 15) } \\
\text { in radians }\end{array}$ & $\begin{array}{l}\text { Phase } \\
\text { Shift } \mathrm{S}_{1} \\
\text { (Eq. 16) } \\
\text { in radians }\end{array}$ & $\begin{array}{l}\text { Reaeration } \\
\text { Coefficient } \\
\text { in } \mathrm{hr}\end{array}$ & $\begin{array}{l}\text { Reaeration } \\
\text { Coefficient } \\
\text { at } 20^{\circ} \mathrm{C} \\
\text { in day }\end{array}$ \\
\hline II-1 & 0.346 & 0.294 & 0.799 & -1.532 & $0.117 *$ & $3.55 *$ \\
\hline II-2 & 2.13 & .277 & 1.092 & -1.518 & .119 & 2.54 \\
\hline II-3 & 0.183 & .127 & 0.430 & -1.301 & $.219 *$ & $5.02 *$ \\
\hline II-4 & 1.77 & .146 & 1.178 & -1.722 & .100 & 2.23 \\
\hline II-5 & 1.16 & .248 & 1.063 & -1.591 & .119 & 2.90 \\
\hline II- 6 & 2.08 & .261 & 1.010 & -1.573 & .143 & 3.34 \\
\hline II -7 & 2.96 & .233 & 1.088 & -1.622 & .126 & 2.76 \\
\hline II-8 & 1.69 & .256 & 1.102 & -1.443 & .113 & 1.54 \\
\hline II-9 & 1.52 & .196 & 1.202 & -1.296 & .089 & 2.06 \\
\hline
\end{tabular}

*Refer to page 34 of the text. 
In order to assure the predominance of the 24-hour periodicity on DO, the squared coherencies corresponding to the 24-hour period between the theoretical sun light intensity and DO, and between the theoretical sun light intensity and saturation concentration of DO were calculated. Also using the computed spectral densities of DO and saturation concentration of DO, the ratios $R_{1}$ and $R_{2}$ were calculated by

$$
\begin{aligned}
& R_{1}=\frac{C_{1}^{2} \cdot \Delta \omega}{\sum_{i=1}^{N}\left(C_{i}^{\prime}\right)^{2} / N} \text { and } \\
& R_{2}=\frac{D_{1}^{2} \cdot \Delta \omega}{\sum_{i=1}^{N}\left(C_{s i}^{\prime}\right)^{2} / N},
\end{aligned}
$$

where, $\sum_{i=1}^{N}\left(C_{i}^{\prime}\right)^{2} / N$ is the total variance of the Do,

$\sum_{i=1}^{N}\left(C_{s i}^{\prime}\right)^{2 / N}$ is the total variance of the saturation concentration of Do,

$C_{1}^{2}$ is the power spectral density of DO corresponding to the 24-hour period, or squared Fourier coefficient of DO corresponding to $n=1$,

$D_{1}^{2}$ is the power spectral density of saturation concentration of DO corresponding to the 24-hour period, or squared Fourier coefficient of $C_{s}^{\prime}$ corresponding to $n=1$,

$N$ is the number of observations given by $N=24 t_{D}$,

$t_{D}$ is the duration of time series data in days, and

$\Delta \omega$ is a bandwidth determined by $\Delta \omega=1 / t_{D}$.

These ratios, $R_{1}$ and $R_{2}$, may be considered as indices of the extent that the 24-hour period component is responsible for the total variance of their fluctuations. The coherencies, the total variances, and the ratios are summarized in table 3 . 


\begin{tabular}{|c|c|}
\hline 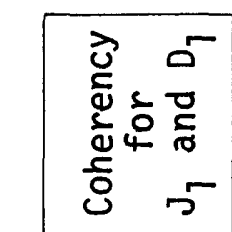 & 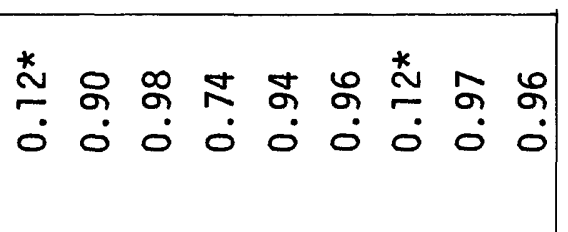 \\
\hline 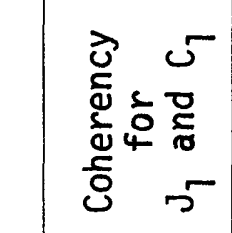 & 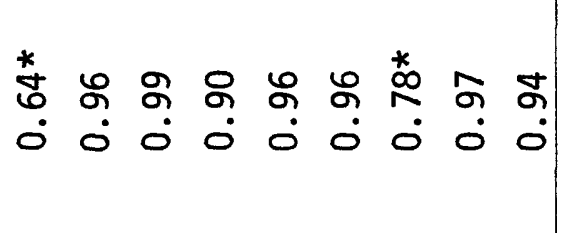 \\
\hline 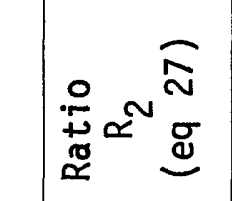 & 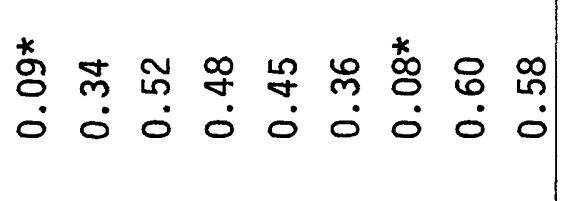 \\
\hline 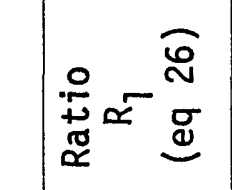 & 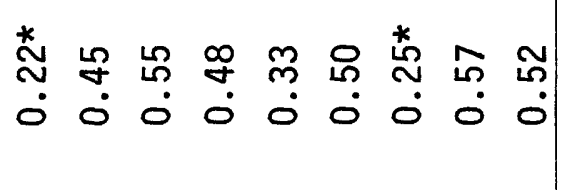 \\
\hline 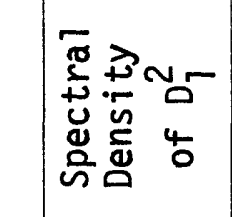 & 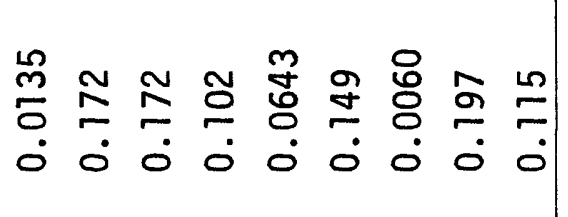 \\
\hline 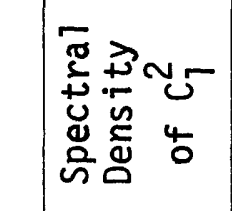 & 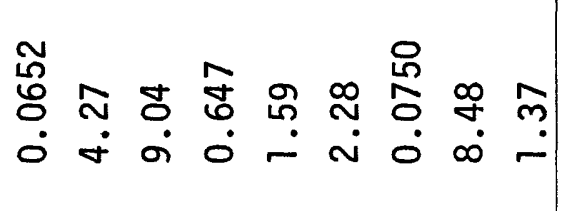 \\
\hline 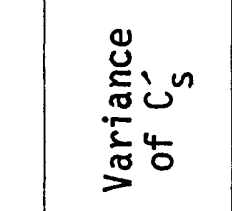 & 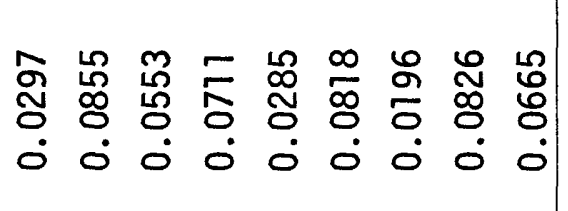 \\
\hline 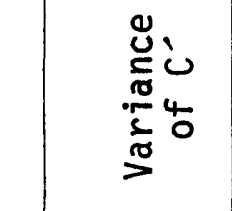 & 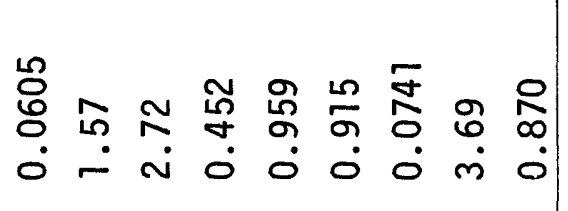 \\
\hline 空產 & 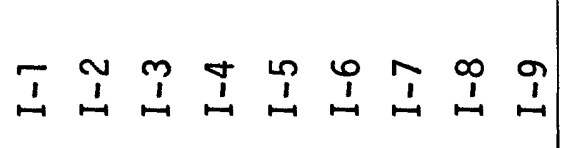 \\
\hline
\end{tabular}




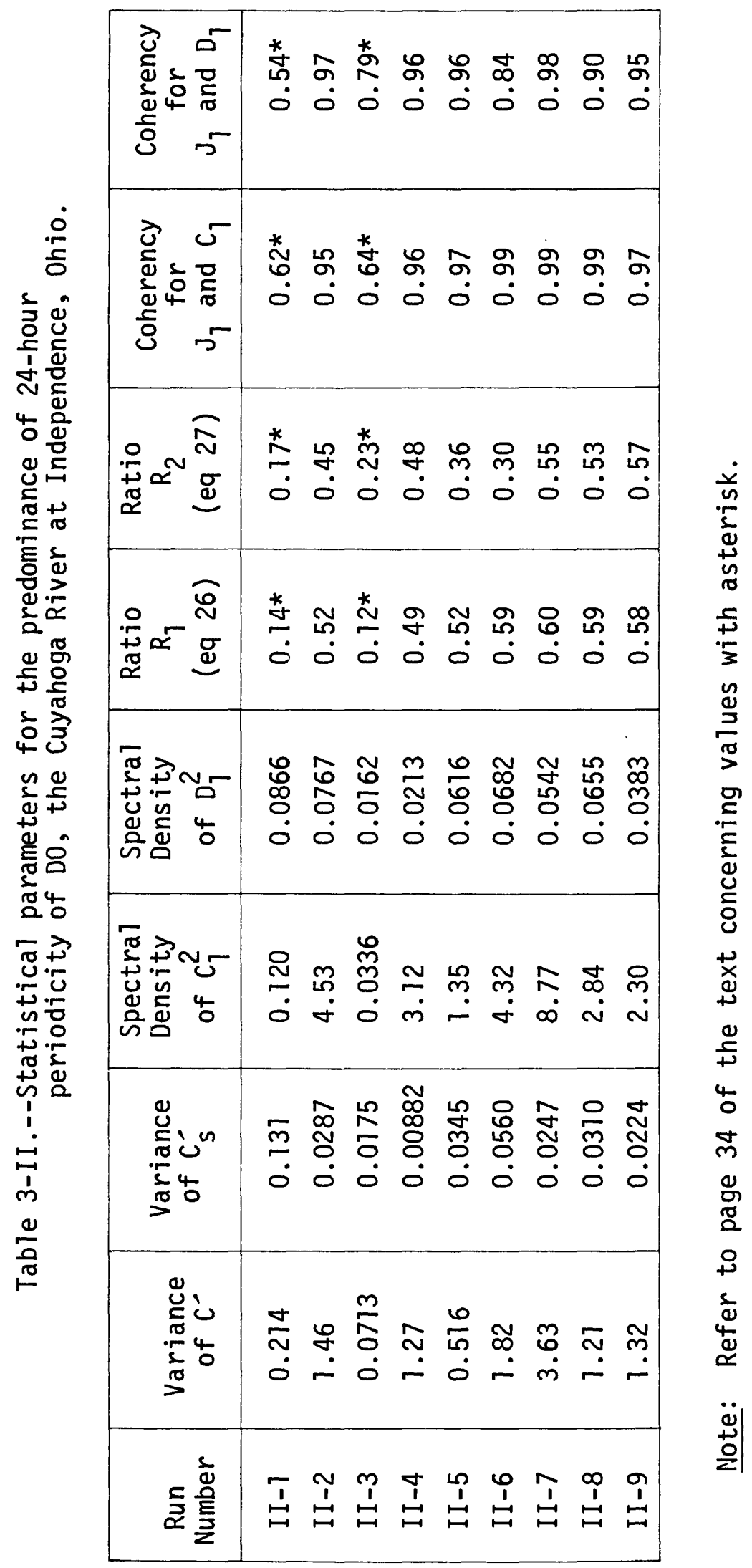


Generally speaking, it can be assumed that the greater the coherency and the ratio, the better the consistency between the model and data. For a practical application, the following numerical criteria have been developed based on the linearity of eq 14 . Namely, 1) $R_{1}$ should be greater than 0.30 , 2) $R_{2}$ should be greater than $\left.0.30,3\right)$ the squared coherency between sun light intensity and DO should be greater than 0.9 , and 4) the squared coherency between sun light intensity and saturation concentration of Do should be greater than 0.7 . Also $T_{1}$, the phase shift, should satisfy the requirement of $0 \leq T_{1} \leq \frac{\pi}{2}$ for $K_{2} \geq 0$. The above criteria were applied to all runs in table 2 and those runs violating the criteria are marked with asterisk in tables 2 and 3.

Comparing these criteria with the physical conditions of the Cuyahoga River, it appears that the present method is not applicable for cases of river discharge greater than $10 \mathrm{~m}^{3} \cdot \mathrm{sec}^{-1}$, water temperature lower than $20^{\circ} \mathrm{C}$, and/or DO less than $3 \mathrm{mg}$. Iiter $^{-1}$. When the river discharge, and thus, the flow velocity is high, the convection of upstream DO conditions may disturb a regular diurnal variation of Do downstream. When the water temperature is low, photosynthetic activities will be depressed and may not show a regular diurnal pattern. These effects will create nonhomogeneous conditions in the reach of interest, which are not compatible with the model assumptions. The present method appears to be usable only for the condition of steady flows with moderate to low discharge rates and with warmer water temperature. On the other hand, such apparent limitations of the present method to the Cuyahoga River may not be detrimental at all because it is well known that low river discharges combined with hot and dry weather present the most critical situation for organic water polution in which the information on reaeration is vital. 
Note that, for Run Number I-9, the value of the phase shift was negative, although the previously mentioned criteria were satisfied. A distinctive feature of this data set was unusually low DO values on the order of 1 to 3 mg:1iter ${ }^{-1}$. Large organic waste loads may have been the cause of this unexpected result.

Regarding diurnal variations of DO in streams, Gunnerson and Bailey (1963) showed interesting results in their intensive surveys of the Sacramento River. They classified the shapes of diurnal Do curves into eight types and calculated the probabilities of their occurrences. According to the probability of occurrence of Type I in the Gunerson-Bailey classification, namely, the minimum DO appearing just before dawn and the maximum DO in mid-afternoon, the possibility of application of the present method appear to be 62 per cent in the upper reach, 48 per cent in the middle reach, 28 per cent in the lower reach and 38 per cent in the pool. In the case of Type III, in which the maximum DO occurrence is shifted to late afternoon or evening, the phase shift should supposedly be greater than $\pi / 2$ and negative $K_{2}$ values could be obtained. It will be necessary to further investigate why negative $K_{2}$ values occur and how the corrections can be made.

One shortcoming of the present method is the possible discrepancy between the actual sun light intensity and the idealized sun light intensity used here. There may be various effects of clouds, smoke, smog, fog, shading as a result of terrain, and other light attenuators. Since this method assumes, as a first-order approximation for the 3-to 6-day averaging period, that the phase shift between the sun light and DO is not critically distorted, it would not account for clouds and other light attenuating effects adequately. This is one of the problems to be left for further investigations. 
(ii) Maximum digitizing interval and minimum time series length

In order to calculate the spectral density for a 24-hour periodic phenomenon, a 12-hour interval is the maximum digitizing interval and a 2-day duration is the minimum length of continuous data needed according to the theory of spectral analysis. These values, however, are not used in practice because precision and resolution of the analysis are greatly impaired when the volume of data is reduced to this level. To investigate optimum volume of data needed, $K_{2}$ values were calculated for different digitizing intervals and for different data lengths for Run No. I-3. The relationship between the $K_{2}$ values and the digitizing intervals are tabulated in table 4 . Computed power spectra of the sun light intensity and DO for shortened durations of 2 days and 3 days are shown in figures 14 to 17 . These results suggest that the optimum digitizing interval should be 1 to 3 hours, and that the minimum time series length should be 3 days.

(iii) Reaeration coefficient and river water discharge

The values of $K_{2}$ are plotted in figure 18 against river discharges, the only hydraulic data available for the Cuyahoga River. The prediction of the reaeration coefficient on the sole basis of discharge has been discussed by More1-Seytoux and Lau (1975). They concluded that six of the seven prediction equations suggested that the reaeration coefficient decreases as the discharge increases. The only exception was the equation quoted by them to be due to Tsivoglou and Wallace, who were not the authors of the quoted report. Tsivoglou and Neal (1976), however, reported a similar relation, with which figure 18 appears to be in qualitative agreement. For practical purposes, the $K_{2}$ values of 7.68 and 2.64 day $^{-1}$ (on the basis of natural logarithm) are considered as the best estimated values at old Portage and Independence, respectively, when the Cuyahoga River has a discharge range of 2.8 to $8.5 \mathrm{~m}^{3} \mathrm{sec}^{-1}$. The difference between the $K_{2}$ values of old Portage 
Table 4. Variation of reaeration coefficient with digitizing interval of time series data (Run I-3 for Cuyahoga River at 01d Portage, Ohio)

\begin{tabular}{|c|c|}
\hline $\begin{array}{c}\text { Digitizing interval } \\
\text { in hours }\end{array}$ & $\begin{array}{c}\text { Reaeration coefficient } \\
\text { at } 20^{\circ} \mathrm{C} \mathrm{in} \mathrm{day}^{-1}\end{array}$ \\
\hline 1 & 5.06 \\
2 & 5.26 \\
3 & 5.14 \\
6 & 7.82 \\
8 & 8.40 \\
12 & $\infty$ \\
\hline
\end{tabular}




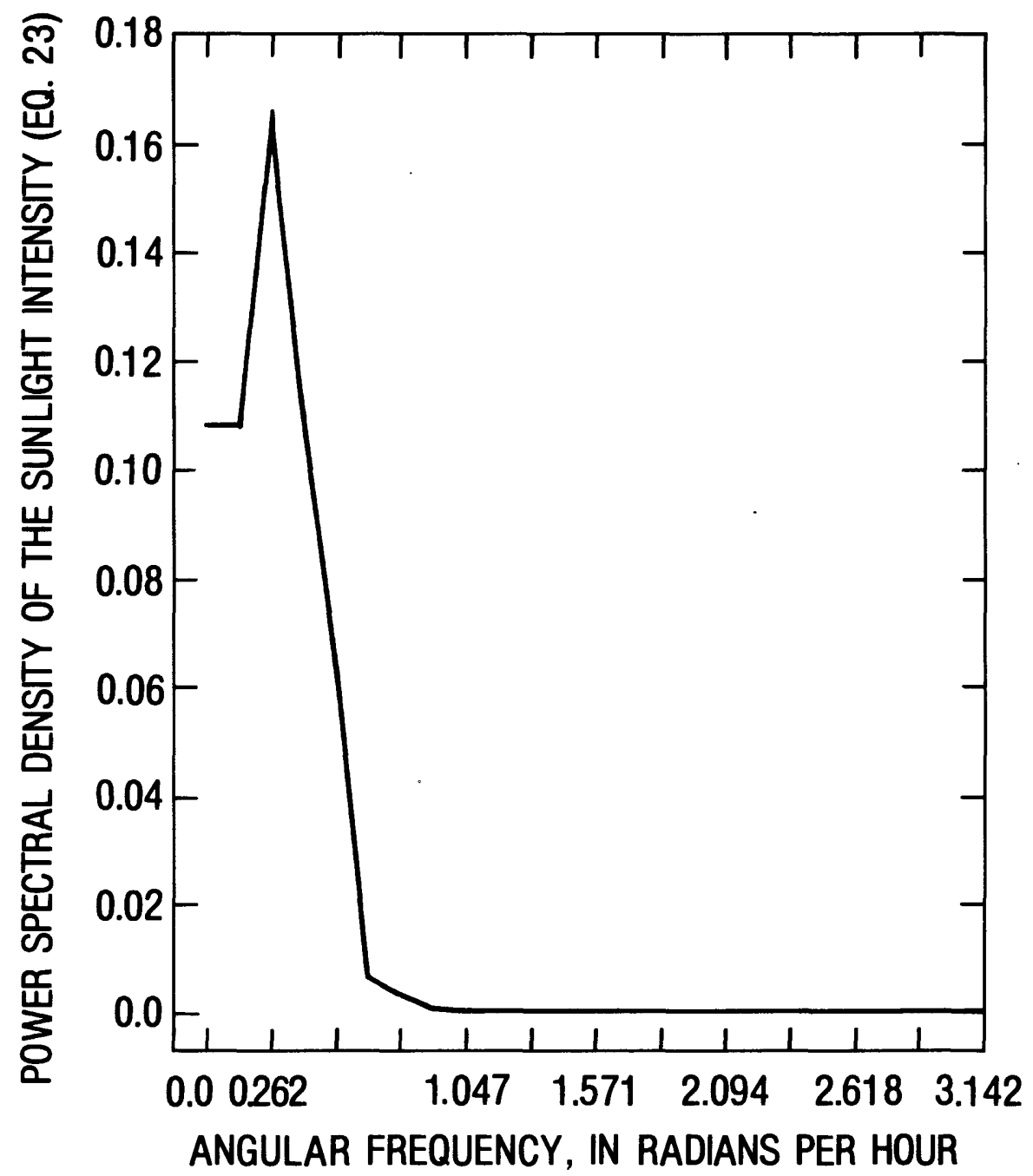

Figure 14.--Power spectrum of sun light intensity, Run I-3, the Cuyahoga River at 01d Portage, Ohio, June 1011, 1976. (Shortened time series) 


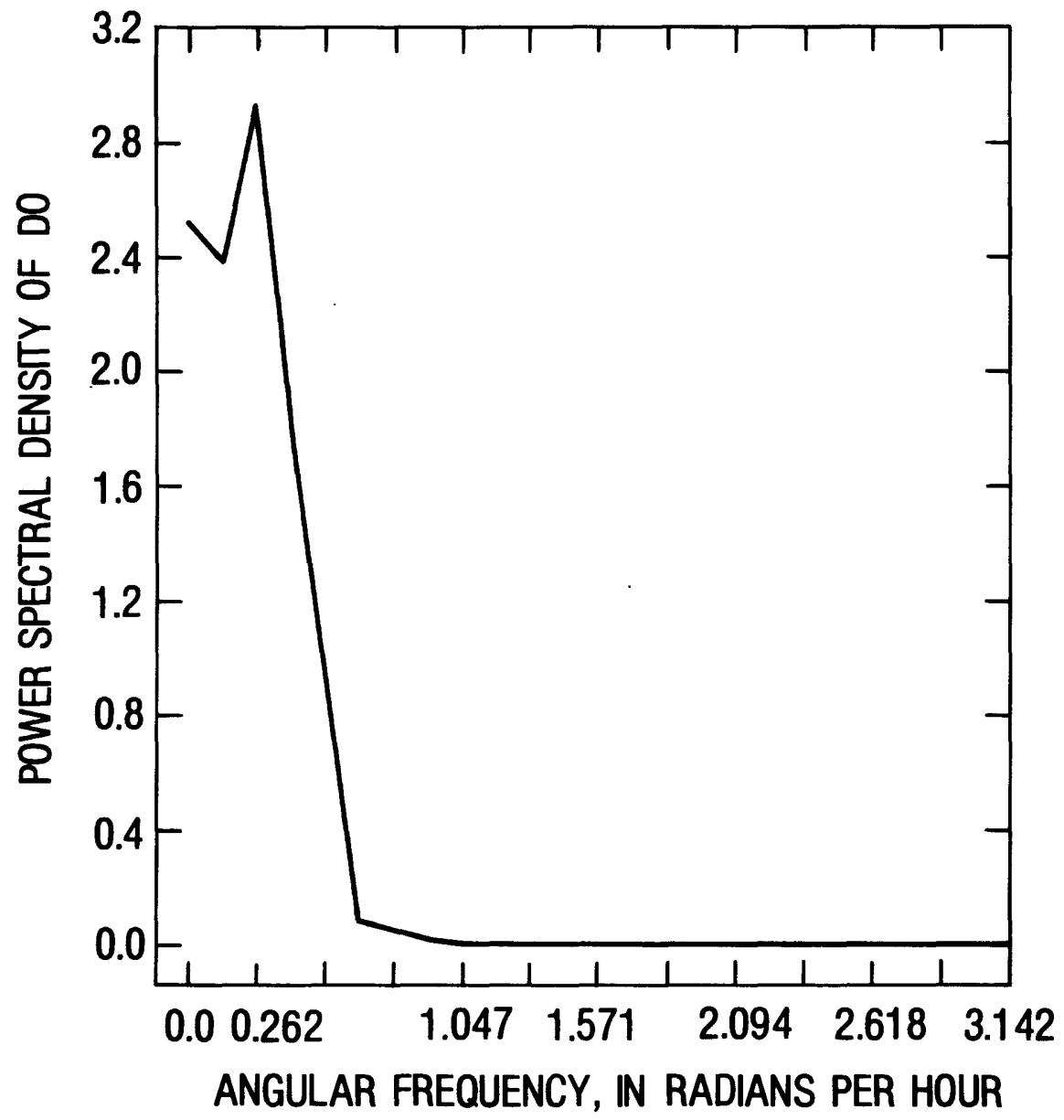

Figure 15.--Power spectrum of DO, Run I-3, the Cuyahoga River at 01d Portage, Ohio, June 10-11, 1976. (Shortened time series) 


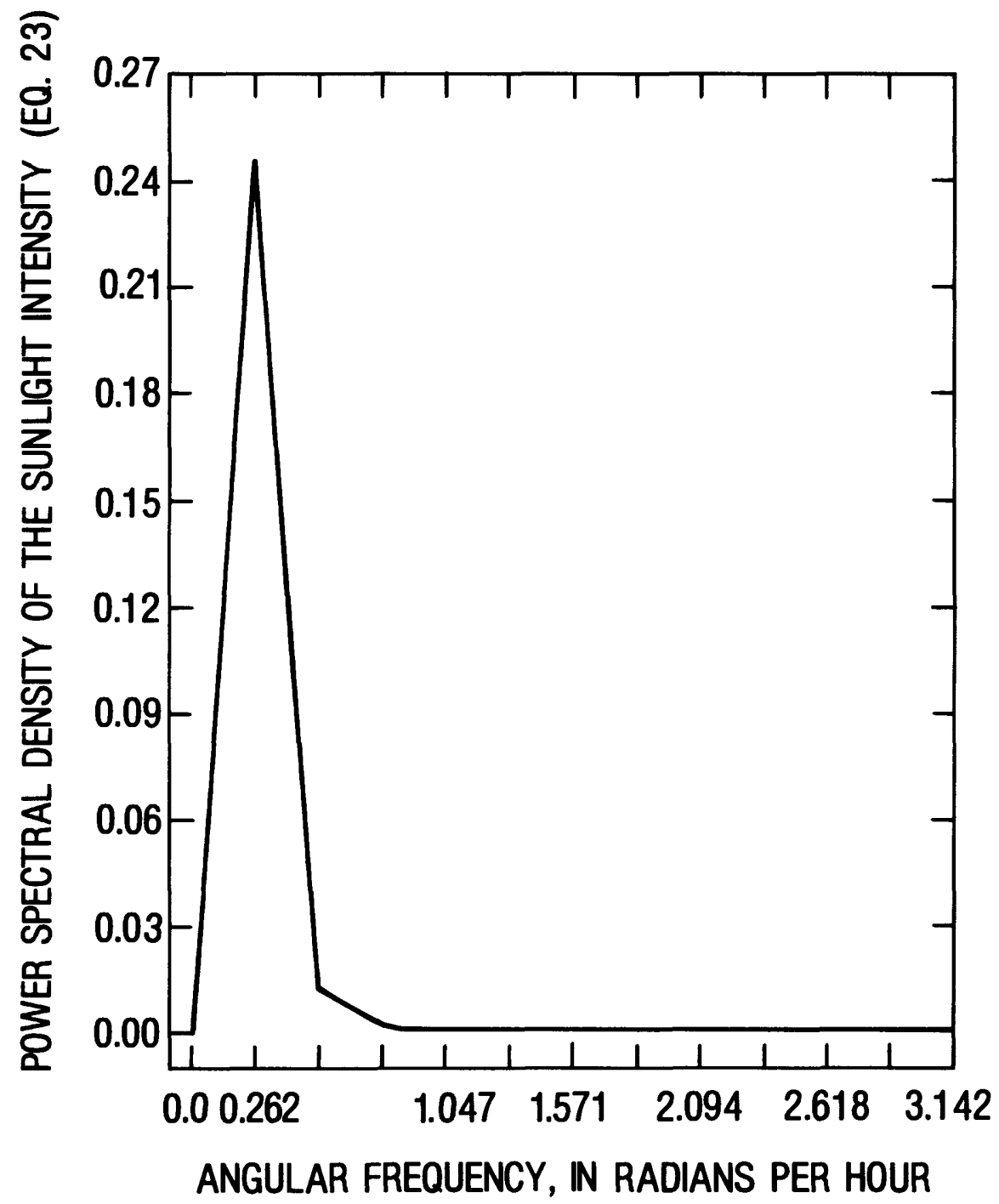

Figure 16.--Power spectrum of sun light intensity, Run I-3, the Cuyahoga River at 01d Portage, Ohio, June 1012, 1976. (Shortened time series) 


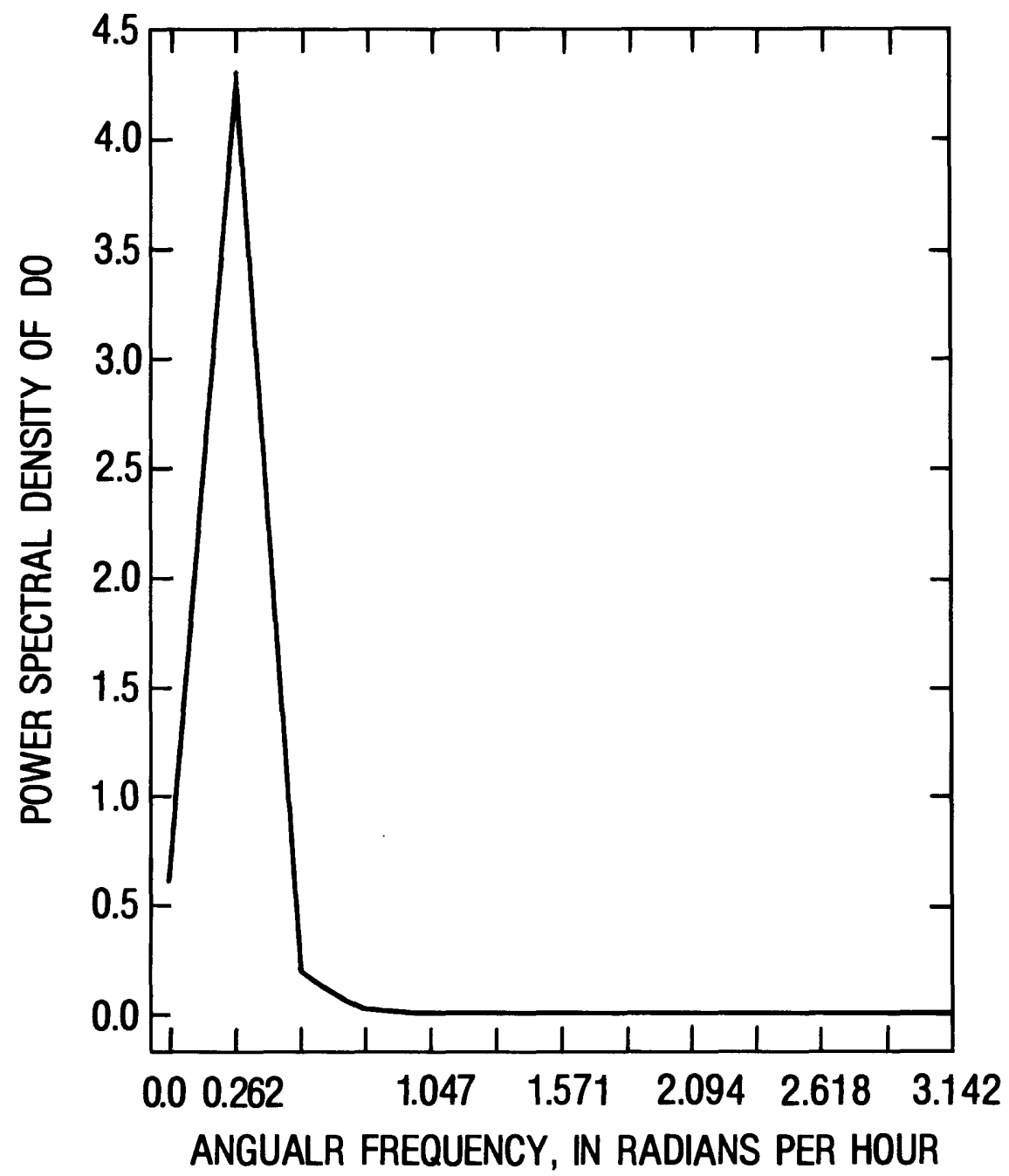

Figure 17.--Power spectrum of DO, Run I-3, the Cuyahoga River at 0ld Portage, Ohio, June 10-12, 1976. (Shortened time series) 

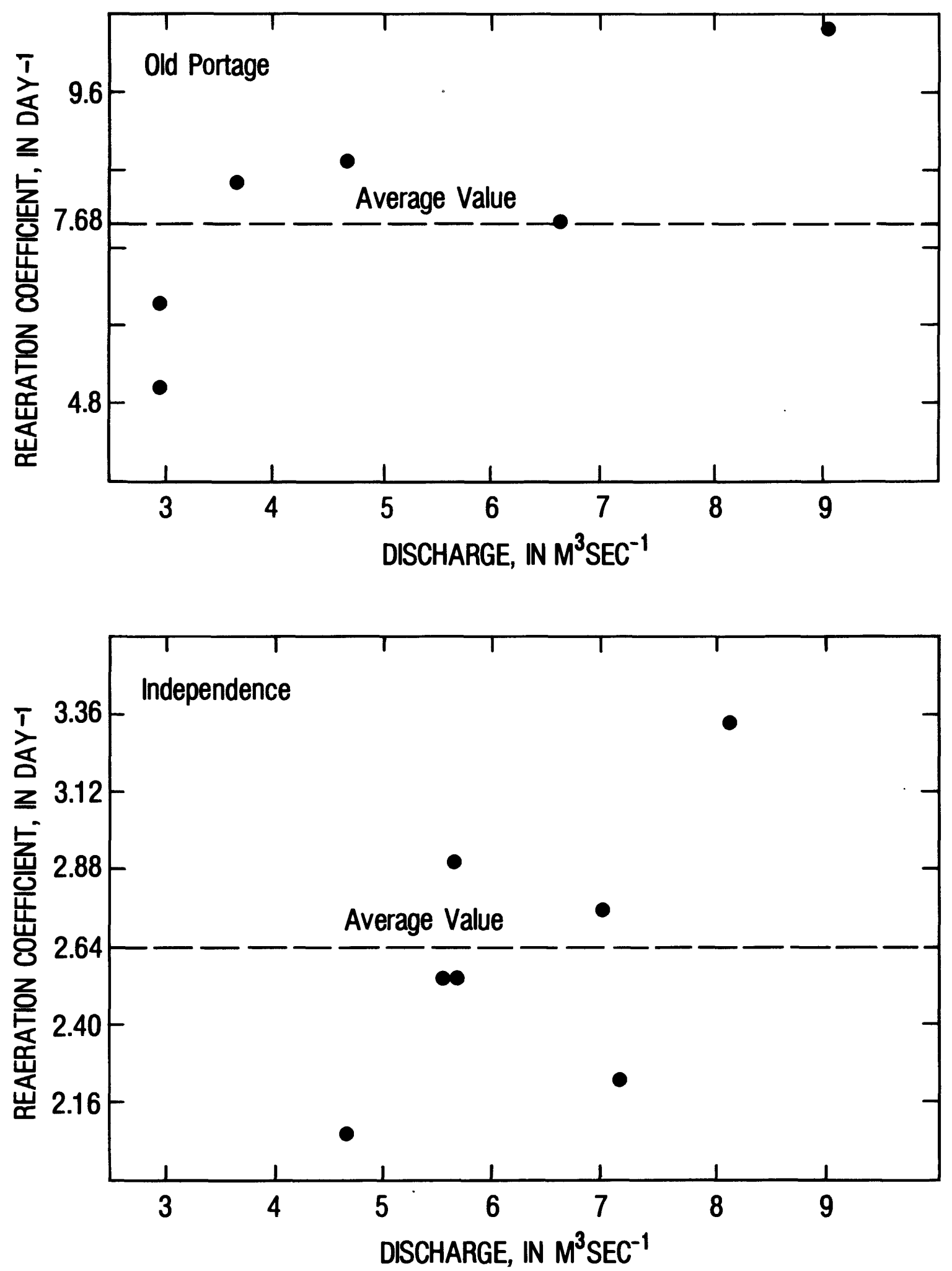

Figure 18.--Relations between reaeration coefficient and river discharge at two stations, the Cuyahoga River, Ohio, 1976-1977. 
and those of Independence is large enough to suggest that the reaeration coefficient may be dependent on local hydraulic and biological conditions even under the same discharge. It may be necessary to properly select the location of a single observation station to obtain an average value over a certain river reach.

\section{CONCLUSIONS}

An analytical model was developed for the reaeration coefficient of a natural stream based on the assumption that, when the reach is hydraulically uniform and biologically homogeneous, the variation of DO is controlled only by time-dependent processes of reaeration and photosynthesis. Spectral analysis of time series data for DO, water temperature, and sun light intensity obtained at a single location of a prototype stream supplies all necessary information for estimation of the eaeration coefficient, the photosynthetic rate, and the BOD deoxygenation rate, provided that certain criteria are satisfied by the statistical properties of the data.

A preliminary application of the method to the Cuyahoga River, Ohio, 19761977, indicates that the method offers a very simple means of calculating the reaeration coefficient when the spectral properties of data show predominance of the diurnal periodicity. In some instances, however, high stream velocity, low water temperature, extremely low Do or their combinations may have produced nonhomogeneous conditions in study reaches to render the application of the method less reliable.

A unique feature of the proposed method is that the spectral analysis provides a consistency check between the data and the model. So long as the data shows such consistency, the present method has potential applications not only for streams but also for estuaries and lakes where the water body is homogeneous and the variation of DO is controlled only by time-dependent processes of reaeration and photosynthesis. 
Substituting eqs 15,16 , and 17 , into eq 14 , eq 14 can be written

as,

$$
\begin{aligned}
& \frac{d}{d t}\left(\sum_{n=1}^{\infty} C_{n} \cos \left(\Omega_{n} t-T_{n}\right)\right)+K_{2} \sum_{n=1}^{\infty} C_{n} \cos \left(\Omega_{n} t-T_{n}\right) \\
& -K_{2} \sum_{n=1}^{\infty} D_{n} \cos \left(\Omega_{n} t-S_{n}\right)=\alpha{ }_{n=1}^{\infty} J_{n} \cos \left(\Omega_{n} t\right)
\end{aligned}
$$

Consider the following differentiation and expansions of terms appearing in eq $A-1$ :

$$
\begin{aligned}
& \frac{d}{d t}\left(\sum_{n=1}^{\infty} C_{n} \cos \left(\Omega_{n} t-T_{n}\right)\right) \\
= & \sum_{n=1}^{\infty}-C_{n} \sin \left(\Omega_{n} t-T_{n}\right) \\
= & \sum_{n=1}^{\infty}-C_{n} \Omega_{n}\left(\sin \left(\Omega_{n} t\right) \cos \left(T_{n}\right)-\cos \left(\Omega_{n} t\right) \sin \left(T_{n}\right)\right) \\
& K_{2} \sum_{n=1}^{\infty} C_{n} \cos \left(\Omega_{n} t-T_{n}\right) \\
= & K_{2} \sum_{n=1}^{\infty} C_{n}\left(\cos \left(\Omega_{n} t\right) \cos \left(T_{n}\right)+\sin \left(\Omega_{n} t\right) \sin \left(T_{n}\right)\right) \\
& K_{2} \sum_{n=1}^{\infty} D_{n} \cos \left(\Omega_{n} t-S_{n}\right) \\
= & K_{2} \sum_{n=1}^{\infty} D_{n}\left(\cos \left(\Omega_{n} t\right) \cos \left(S_{n}\right)+\sin \left(\Omega_{n} t\right) \sin \left(S_{n}\right)\right)
\end{aligned}
$$

By substituting eqs $A-2, A-3$, and $A-4$ into eq $A-1$, eq $A-1$ is arranged to the form

$$
\begin{aligned}
& \sum_{n=1}^{\infty}\left(C_{n} \Omega_{n} \sin \left(T_{n}\right)+K_{2} C_{n} \cos \left(T_{n}\right)-K_{2} D_{n} \cos \left(S_{n}\right)\right) \cos \left(\Omega_{n} t\right) \\
- & \sum_{n=1}^{\infty}\left(C_{n} \Omega_{n} \cos \left(T_{n}\right)-K_{2} C_{n} \sin \left(T_{n}\right)+K_{2} D_{n} \sin \left(S_{n}\right)\right) \sin \left(\Omega_{n} t\right) \\
= & \alpha \sum_{n=1}^{\infty} J_{n} \cos \left(\Omega_{n} t\right)
\end{aligned}
$$


Because of the orthogonality of $\cos \left(\Omega_{n} t\right)$ and $\sin \left(\Omega_{n} t\right)$, eq A-5 requires that coefficients of $\cos \left(\Omega_{n} t\right)$ and $\sin \left(\Omega_{n} t\right)$ must be independently zero, or

$$
\begin{aligned}
& C_{n} \Omega_{n} \cos \left(T_{n}\right)-K_{2}\left(C_{n} \sin \left(T_{n}\right)-D_{n} \sin \left(S_{n}\right)\right)=0 \\
& C_{n} \Omega_{n} \sin \left(T_{n}\right)+K_{2}\left(C_{n} \cos \left(T_{n}\right)-D_{n} \cos \left(S_{n}\right)\right)=\alpha J_{n}
\end{aligned}
$$

Eqs 21 and 22 may be obtained easily from eqs A-6 and A-7, respectively.

Eq 22 may also be written as

$$
\alpha=\frac{C_{n} \Omega_{n}\left(C_{n}-D_{n} \cos \left(T_{n}-S_{n}\right)\right)}{J_{n}\left(C_{n} \sin \left(T_{n}\right)-D_{n} \sin \left(S_{n}\right)\right)} .
$$


Barr, A. J., Goodnight, J. H., Sall, J. P., and Helwig, J. T., 1976, A user's guide to SAS 76: SAS Institute Inc., 329p.

Bennett, J. P. and Rathbun, R. E., 1971, Reaeration in open-channel flow: U.S. Geol. Survey Open-File Report, Fort Collins, Colorado, 314p.

Brown, L. C., 1974, Statistical evaluation of reaeration prediction equation:, Jour. of the Environmental Eng. Div., Am. Soc. of Civil Engineering, v. 100, no. EE5, pp. 1051-1068.

Camp, T. R., 1965, Field estimation of oxygen balance parameters: Jour. of the Sanitary Eng. Div., Am. Soc. of Civil Engineering, v. 91, no. SA5, pp. 1-16.

Churchill, M. A., Elmore, H. L., and Buckingham, R. A., 1962, The prediction of stream reaeration rates: Jour. of the Sanitary Eng. Div. Am. Soc. of Civil Engineering, v. 88, no. SA4, pp. 1-46.

Dobbins, W. E., 1964, BOD and oxygen relationships in streams: Jour. of the Sanitary Eng. Div., Am. Soc. of Civil Engineering, v. 90, no. SA3, pp. 53-78.

Elmore, H. L., and West, W. F., 1961, Effect of water temperature on stream reaeration: Jour. of the Sanitary Eng. Div., Am. Soc. of Civil Engineering, v. 87, no. SA6, pp. 59-71.

Gunnerson, C. G., and Bailey, T. E., 1963, Oxygen relationships in the Sacramento River: Jour. of the Sanitary Eng. Div., Am. Soc. of Civil Engineering, v. 89, no. SA4, pp. 95-124.

Jackman, A. P., and Yotsukura, N., 1977, Thermal loading of natural streams: U.S. Geol. Survey Prof. Paper 991, 39p.

Jenkins, G. M., and Watts, D. G., 1968, Spectral analysis and its applications: Holden-Day, Inc., San Francisco, California, 525p.

Kelly, M. G., Hornberger, G. M., and Cosby, B.J., 1974, Continuous automated measurement of rates of photosynthesis and respiration in an undisturbed river community: Limnology and Oceanography, v. 19, no. 2, pp. 305-312. 
Morel-Seytoux, H. J., and Lau, D. H., 1975, Discussion of Statistical evaluation of reaeration prediction equations, by L. C. Brown: Jour. of the Environmental Eng. Div., Am. Soc. of Civil Engineering, v. 101, no. EE5, pp. 859-861.

O'Connor, D. J., and Di Toro, D. M., 1970, Photosynthesis and oxygen balance in stream: Jour. of Environmental Eng. Div., An. Soc. of Civil Engineering, v. 96, no. SA2, pp. 547-571.

O'Connor, D.J., and Dobbins, W.E., 1958, Mechanism of reaeration in natural Streams: Transactions, Am. Soc. of Civil Engineering, v. 123, pp. 641-666.

Peters, J.G., Crawford, C. G., and Wilber, W.G., 1980, A one-dimensional steady-state, dissolved-oxygem model and waste-load assimilation study for Little Lick and Big Lick Creeks, Blackford and Delaware Counties, Indiana: U.S. Geol. Survey Open-file Report 80-73, 102p.

Rathbun, R. E., 1977, Rearation coefficients of streams: state-of-the-art: Jour. of the Hydraulics Div. Am. Soc. of Civil Engineering, v. 103, no. HY4, pp. 409-424.

Sayre, W. W., and Chang, F. M., 1968, A laboratory investigation of open-channe1 dispersion processes for dissolved, suspended, and floating dispersants: U.S. Geo1. Survey Prof. Paper 433-E., 71p.

Schurr, J. M., and Ruchti, J., 1977, Dynamics of $\mathrm{O}_{2}$ and $\mathrm{CO}_{2}$ exchange, photosynthesis, and respiration in rivers from time-delayed correlation with ideal sunlight: Limnology and Oceanography, v. 22, no. 2, pp. 208-225.

Streeter, H. W., and Phelps, E. B., 1925, A study of the pollution and natual purification of the Ohio River: Public Health Bulletin 146, U.S. Public Health Service, Washington, D.C., 75p.

Thackston, E. L., and Krenke1, P. A., 1969, Reaeration prediction in natural streams: Jour. of the Sanitary Eng. Div., Am. Soc. of Civil Engineering, v. 95 , bo. SA1, pp. 65-94.

Tsivoglou, E. C., and Neal, L. A., 1976, Tracer measurement of reaeration; III. Predicting the reaeration capacity of inland streams: Jour. of Water Pollution Control Fed., v. 48, no. 12, pp. 2669-2689. 